\title{
Prehospital resuscitation with hypertonic saline- dextran modulates inflammatory, coagulation and endothelial activation marker profiles in severe traumatic brain injured patients
}

Shawn G Rhind ${ }^{1,2^{*}}$, Naomi T Crnko ${ }^{3}$, Andrew J Baker ${ }^{4,5}$, Laurie J Morrison ${ }^{6}$, Pang N Shek ${ }^{1,3}$, Sandro Scarpelini ${ }^{7}$, Sandro B Rizoli ${ }^{7}$

\begin{abstract}
Background: Traumatic brain injury (TBI) initiates interrelated inflammatory and coagulation cascades characterized by wide-spread cellular activation, induction of leukocyte and endothelial cell adhesion molecules and release of soluble pro/antiinflammatory cytokines and thrombotic mediators. Resuscitative care is focused on optimizing cerebral perfusion and reducing secondary injury processes. Hypertonic saline is an effective osmotherapeutic agent for the treatment of intracranial hypertension and has immunomodulatory properties that may confer neuroprotection. This study examined the impact of hypertonic fluids on inflammatory/coagulation cascades in isolated head injury.
\end{abstract}

Methods: Using a prospective, randomized controlled trial we investigated the impact of prehospital resuscitation of severe TBI (GCS < 8) patients using 7.5\% hypertonic saline in combination with $6 \%$ dextran-70 (HSD) vs $0.9 \%$ normal saline (NS), on selected cellular and soluble inflammatory/coagulation markers. Serial blood samples were drawn from 65 patients (30 HSD, 35 NS) at the time of hospital admission and at 12, 24, and 48-h postresuscitation. Flow cytometry was used to analyze leukocyte cell-surface adhesion (CD62L, CD11b) and degranulation (CD63, CD66b) molecules. Circulating concentrations of soluble (s)L- and SE-selectins (SL-, SEselectins), vascular and intercellular adhesion molecules (sVCAM-1, sICAM-1), pro/antiinflammatory cytokines [tumor necrosis factor (TNF)- $\alpha$ and interleukin (IL-10)], tissue factor (STF), thrombomodulin (sTM) and D-dimers (D-D) were assessed by enzyme immunoassay. Twenty-five healthy subjects were studied as a control group.

Results: TBI provoked marked alterations in a majority of the inflammatory/coagulation markers assessed in all patients. Relative to control, NS patients showed up to a 2-fold higher surface expression of CD62L, CD11b and CD66b on polymorphonuclear neutrophils (PMNs) and monocytes that persisted for 48-h. HSD blunted the expression of these cell-surface activation/adhesion molecules at all time-points to levels approaching control values. Admission concentrations of endothelial-derived SVCAM-1 and SE-selectin were generally reduced in HSD patients. Circulating SL-selectin levels were significantly elevated at 12 and 48 , but not $24 \mathrm{~h}$ post-resuscitation with HSD. TNF- $\alpha$ and IL-10 levels were elevated above control throughout the study period in all patients, but were reduced in HSD patients. Plasma STF and D-D levels were also significantly lower in HSD patients, whereas STM levels remained at control levels.

Conclusions: These findings support an important modulatory role of HSD resuscitation in attenuating the upregulation of leukocyte/endothelial cell proinflammatory/prothrombotic mediators, which may help ameliorate secondary brain injury after TBI.

Trial registration: NCT00878631.

\footnotetext{
* Correspondence: shawn.rhind@drdc-rddc.gc.ca

'Defence Research and Development Canada (DRDC), Toronto, Canada
} 


\section{Background}

Traumatic brain injury (TBI) remains a leading cause of death and persistent neurocognitive impairment in civilian and military casualties [1]. The extent of brain damage is determined by the severity of primary mechanical injury and intensity of secondary biomolecular injury cascades causing neuroinflammation that contributes to cerebral edema, raised intracranial pressure and delayed cellular destruction [2]. TBI patients are also vulnerable to ensuing pathophysiological insults including hypotension and hypoxemia [3], initiating global ischemia/reperfusion and systemic immunoinflammatory responses that worsen neurological outcome and often lead to development of multiorgan dysfunction $[4,5]$.

Prehospital care is a major determinant of long-term outcome in TBI patients. Current management involves expeditious infusion of crystalloids and colloids to limit secondary insults by hemodynamic stabilization and optimization of cerebral perfusion [6]. Yet, the ideal fluid for initial resuscitation of TBI remains unclear [7]; due to in part to a lack of adequately powered clinical trials comparing osmotic agents in neurotrauma [8]. Overzealous crystalloid resuscitation often serves to exacerbate delayed posttraumatic complications, including inflammatory-mediated cellular injury via enhanced cytokine release, endothelial activation, adhesion molecule expression and coagulopathy [9]. Conversely, resuscitation with hypertonic saline, alone or combined with dextran (HS/D), is emerging as effective first-line osmotherapeutic alternative for treatment of intracranial hypertension and cerebral edema [10,11]. Beyond its osmotic and hemodynamic properties, compelling laboratory and clinical data indicate that HS/D exerts immunomodulatory and antiinflammatory effects [12-15], including blunted cellular activation, cytokine production and adhesion molecule expression, that may also convey neuroprotection against brain secondary injury cascades $[16,17]$.

It is increasingly evident that TBI elicits interdependent CNS and systemic inflammatory and coagulation cascades that contribute to secondary neuropathological sequelae $[4,18]$. These innate host defence responses to cerebral insults are characterized by rapid activation of resident microglia and astrocytes [19], brain microvascular ECs [20] and peripheral blood leukocytes (PMNs, monocytes) [21,22], with increased expression of multiple surface-active and soluble mediators, including inflammatory cytokines [23], adhesion molecules $[24,25]$ and coagulation cofactors $[18,26]$. TNF- $\alpha$ is a central mediator of neuroinflammation after brain injury [19], inducing generalized endothelial activation/injury [27], direct neurotoxicity [28], reduced $\mathrm{BBB}$ integrity $[23,29]$, and upregulated adhesion molecule expression [24,25,30], thus promoting leukocyte-EC interactions and cellular infiltration of injured brain parenchyma [31,32].

Based on the multi-step paradigm of leukocyte trafficking, inflammatory cells are recruited into the microvasculature via sequential adhesive interactions of selectins and integrins with their respective immunoglobulin family ligands [29]. Initial tethering and rolling of marginated cells along the vessel wall is mediated by $\mathrm{L}$ (leukocyte; CD62L) and E- (endothelial; CD62E) selectins binding to sialyl-Lewis ${ }^{\mathrm{X}}$ carbohydrate counterreceptors. Subsequent $\beta_{2}$-integrin (CD11b)-dependent firm adhesion to endothelial ligands for intercellular and vascular cell adhesion molecules (ICAM-1, CD54; VCAM-1, CD106) allows leukocyte transmigration into damaged tissues [31]. Simultaneously, ligand-binding triggers leukocyte effector functions, such as respiratory burst and degranulation of azurophilic (CD63) and specific (CD66b) proteins [33]. Sequestration of activated leukocytes within the CNS inflicts secondary injury through generation of neurototoxic reactive species, granular proteases, and inflammatory cytokines, ultimately producing endothelial destruction, thrombosis and end-organ failure [34,35].

The vascular endothelium provides a critical interface for host inflammatory and coagulation responses to injury. Cytokine-activated or damaged ECs participate in hemostatic balance via synthesis of procoagulant TF and anticoagulant TM endothelial glycoproteins [36]. TBI patients are prone to coagulation abnormalities since the brain is rich in TF [26], which initiates the extrinsic pathway causing local and systemic hemostatic disturbances [37]. TNF- $\alpha$ is also a potent inducer of TF by ECs and monocytes [38,39], but inhibits cell-surface expression of TM [40], thus shifting the hemostatic balance towards intravascular thrombosis and hyperfibrinolysis with release of D-D fibrin degradation products [41]. Soluble isoforms of adhesion and coagulation molecules are also liberated during inflammation serving as circulating markers of endothelial activation or injury [42]. Collectively, these changes exemplify the molecular crosstalk between coagulation-inflammatory pathways as a key aspect in secondary brain injury progression $[26,43]$.

In light of our previous findings in the same cohort of TBI patients [44] showing dramatically elevated S100B, NSE, and MBP brain-injury biomarkers in serum from patients resuscitated with NS relative to HSD-treated patients, along with the knowledge that these specific cellular injury markers are associated with disruption of the $\mathrm{BBB}$ and neuroinflammation $[45,46]$, we hypothesized that prehospital resuscitation of head injury patients using $7.5 \%$ hypertonic saline with $6 \%$ dextran- 
Table 1 Patient demographics and clinical characteristics on admission according to prehospital fluid resuscitation treatment groups.

\begin{tabular}{|c|c|c|c|}
\hline \multirow[t]{2}{*}{ Variables } & \multicolumn{2}{|c|}{ Resuscitation Group } & \multirow[t]{2}{*}{$P$ Value $^{\dagger}$} \\
\hline & $H S D$ & NS & \\
\hline \multicolumn{4}{|l|}{ Demographics } \\
\hline $\begin{array}{l}\text { No. of Patients, } \\
n\end{array}$ & 30 & 35 & \\
\hline Age, yrs & $41.8 \pm 17.4$ & $42.8 \pm 18.8$ & $0.85^{\mathrm{a}}$ \\
\hline $\begin{array}{l}\text { Sex Ratio } \\
(M / F)\end{array}$ & $19 / 11$ & $25 / 10$ & $0.79^{c}$ \\
\hline \multicolumn{4}{|l|}{ Vital signs } \\
\hline $\begin{array}{l}\text { GCS on } \\
\text { Admission }\end{array}$ & $5.6 \pm 2.8$ & $5.9 \pm 2.6$ & $0.53^{b}$ \\
\hline $\mathrm{SBP}, \mathrm{mm} \mathrm{Hg}$ & $133.3 \pm 16.2$ & $130.8 \pm 28.3$ & $0.83^{a}$ \\
\hline 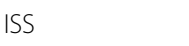 & $34.9 \pm 9.5$ & $31.7 \pm 14.6$ & $0.19^{b}$ \\
\hline APACHE $\|$ & $12.5 \pm 5.9$ & $14.8 \pm 5.1$ & $0.24^{b}$ \\
\hline SOFA & $4.9 \pm 1.7$ & $4.9 \pm 2.5$ & $0.72^{b}$ \\
\hline MODS & $3.8 \pm 1.5$ & $5.0 \pm 3.3$ & $0.64^{b}$ \\
\hline \multicolumn{4}{|l|}{$\begin{array}{l}\text { Laboratory } \\
\text { Values }\end{array}$} \\
\hline $\mathrm{Hb}, \mathrm{g} / \mathrm{dL}$ & $11.3 \pm 1.6$ & $11.9 \pm 2.1$ & $0.39^{a}$ \\
\hline $\mathrm{Hct}, \%$ & $32.9 \pm 5.0$ & $34.7 \pm 5.9$ & $0.40^{a}$ \\
\hline Plt, $10^{9} / \mathrm{L}$ & $206.2 \pm 41.5$ & $219.5 \pm 56.4$ & $0.40^{\mathrm{a}}$ \\
\hline $\mathrm{pH}$ & $7.34 \pm 0.06$ & $7.33 \pm 0.05$ & $0.69^{b}$ \\
\hline $\mathrm{BE}, \mathrm{mEq} / \mathrm{L}$ & $-2.1 \pm 3.2$ & $-2.4 \pm 3.7$ & $0.76^{\mathrm{a}}$ \\
\hline aPTT, s & $26.2 \pm 5.3$ & $24.4 \pm 6.1$ & $0.63^{a}$ \\
\hline INR & $1.08 \pm 0.21$ & $1.12 \pm 0.23$ & $0.25^{\mathrm{b}}$ \\
\hline $\mathrm{Na}, \mathrm{mmol} / \mathrm{L}$ & $146.9 \pm 4.5$ & $143.5 \pm 5.2$ & $0.03^{a}$ \\
\hline $\mathrm{Cl}, \mathrm{mmol} / \mathrm{L}$ & $115.4 \pm 5.0$ & $111.9 \pm 7.0$ & $0.07^{a}$ \\
\hline $\begin{array}{l}\text { Osmolality, } \\
\mathrm{mOsm} / \mathrm{kg}\end{array}$ & $316.0 \pm 20.1$ & $306.7 \pm 29.1$ & $0.05^{\mathrm{a}}$ \\
\hline \multicolumn{4}{|l|}{ Fluids } \\
\hline $\begin{array}{l}\text { Total fluids } \\
\text { prehospital, L }\end{array}$ & $0.4 \pm 0.3$ & $0.3 \pm 0.1$ & $0.83^{a}$ \\
\hline $\begin{array}{l}\text { Total fluids in- } \\
\text { hospital, L }\end{array}$ & $5.4 \pm 2.2$ & $5.3 \pm 2.5$ & $0.96^{\mathrm{a}}$ \\
\hline \multicolumn{4}{|l|}{ Outcomes } \\
\hline GOS & $3.7 \pm 1.3$ & $3.5 \pm 1.5$ & $0.81^{b}$ \\
\hline $\begin{array}{l}\text { Length of stay, } \\
\text { d }\end{array}$ & $14.1 \pm 13.6$ & $14.7 \pm 12.5$ & $0.90^{a}$ \\
\hline $\begin{array}{l}\text { Mechanical } \\
\text { Ventilation, d }\end{array}$ & $6.6 \pm 5.2$ & $9.1 \pm 5.8$ & $0.71^{a}$ \\
\hline $\begin{array}{l}\text { Mortality, } \\
n(\%)\end{array}$ & $4(13.3)$ & $6(17.1)$ & $0.67^{c}$ \\
\hline
\end{tabular}

Abbreviations (normal ranges): NS, normal saline; HSD, hypertonic saline plus dextran; GCS, Glasgow Coma Scale; ISS, Injury Severity Score; APACHE II, Acute Physiologic and Chronic Health Evaluation; SOFA, Sequential Organ Failure Assessment; MODS, Multiple Organ Dysfunction Score; Hb, hemoglobin (1218); Hct, hematocrit (37-52); Plt, platelets (130-400); aPTT, activated partial thromboplastin time (25-35 s); INR, International Normalized Ratio (0.8-1.2); BE, base excess (-2/+2); pH (7.35-7.45); GOS, Glasgow Outcome Scale score. Unless otherwise stated, results are expressed as mean \pm standard deviation (SD); ${ }^{\dagger}$ statistical significance of differences between resuscitation treatment groups were assessed with ${ }^{\mathrm{a}} t$-test, ${ }^{\mathrm{b}} \mathrm{Mann}$-Whitney $U$-test, or ${ }^{\mathrm{c}} \mathrm{Chi}$-square test as appropriate, with significance set at $P<.05$.
70 (HSD) would attenuate the expression of selected cellular and soluble inflammatory/coagulation markers related to secondary brain injury cascades.

\section{Materials and methods \\ Patients and Controls}

Using as an a priori subgroup analysis within our previously reported, larger prospective randomized controlled trial to evaluate hypertonic fluid resuscitation [47], biomarkers of leukocyte and EC activation, inflammation and coagulation were studied in sixty-five severe TBI patients (Table 1). Patients were eligible for the study if at any time during prehospital care they experienced loss of consciousness due to isolated blunt head trauma and/or had a Glasgow Coma Scale (GCS) score of 8 or less. Patients were excluded if they had primary penetrating injury, had suffered severe life-threatening injury to organs other than the brain, received previous intravenous fluid therapy $\geq 50 \mathrm{~mL}$, a time interval between arrival at scene and vascular access which exceeded 4 hours, were younger than 16 years, were pregnant, or had vital signs absent prior to randomization. The Phase II study was approved by the Research Ethics Boards of all participating agencies, along with the Canadian Therapeutic Products Directorate and registered at ClinicalTrials.gov (Identifier: NCT00878631). Prehospital informed consent was waived in accordance with the Tri-Council Policy Agreement for Research in Emergency Health Situations (Article 2.8). Patients were enrolled by advance life support or critical care paramedics, and informed consent was subsequently waived for blood sampling for this substudy. An age-matched $(38.8 \pm 8.5$ yrs $)$ control group of 25 asymptomatic adult donors, with no history of brain injury, were analyzed for determination of the selected cellular and soluble biomarkers after obtaining informed consent. Studies on human subjects were carried out according to the principles of the Declaration of Helsinki.

\section{Study Design and Procedures}

Eligible adult patients were randomly assigned to receive either a single prehospital bolus infusion of $250-\mathrm{mL}$ of $7.5 \%$ hypertonic saline admixed with $6 \%$ dextran-70 (HSD; RescueFlow ${ }^{\bullet}$ BioPhausia AB, Stockholm Sweden) as the experimental treatment, or $250-\mathrm{mL}$ of the standard $0.9 \%$ normal saline (NS). Paramedics administered the treatment solutions as the initial resuscitation fluid given within 4 hours of the incident. After administration of the study fluid, all subsequent clinical treatment was performed according to best practice guidelines established by the American College of Surgeons Advanced Trauma Life Support (ATLS; http://www.facs. org/trauma/atls/edguidelines.html) and the Brain 
Trauma Foundation (BTF; http://www.braintrauma.org/ site $/$ PageServer ? pagename $=$ Guidelines $)$. This included ongoing resuscitation by prehospital personnel with additional crystalloid as per existing protocols. At no point during initial or subsequent treatment was the standard-of-care withheld. Clinical data collected upon hospital admission included age, gender, mechanism of injury, and Injury Severity Score (ISS). Acute neurologic status was assessed by paramedics at the accident scene prior to resuscitation based on the patient's level of consciousness as categorized by GCS score. Motor response, verbal response and response to pain were noted, producing a total score from 3-15; with a range of 3-8 indicating severe injury. Severity of illness and organ dysfunctions was quantified and defined by Acute Physiologic and Chronic Health Evaluation (APACHE II), Sequential Organ Failure Assessment (SOFA) and Multiple Organ Dysfunction Score (MODS) at the time of admission to the ICU. In addition, neurological outcome at the time of hospital discharge (or $\leq 30$ days) was assessed in consenting patients using the Glasgow Outcome Scale (GOS). The GOS is the most widely used method to describe overall outcome after head injury and is based upon the ability of recovering TBI patients to perform activities of daily living and the degree of assistance required. GOS was graded as follows: 1, indicates death; 2 , persistent vegetative state; 3 , severely disabled; 4, moderately disabled; 5 , good recovery. GOS scores were further dichotomized into Good (GOS 4-5) or Poor (GOS 1-3) outcome, as previously described [44].

\section{Blood Sample Collection}

Serial venous blood samples (totaling $25 \mathrm{~mL}$ ) were drawn from each patient as soon as possible after admission to the emergency department and again at 12-, 24- and 48-h post-resuscitation. Specimens for cellular and soluble biomarker analyses were obtained from patients and controls using an evacuated tube collection system containing the appropriate anticoagulants or nonadditive tubes (Vacutainer, Becton Dickinson, Rutherford, NJ).

\section{Routine Clinical Hematology and Coagulation Analyses}

Whole blood samples collected into trisodium citrate and $K_{2}$ EDTA tubes (Becton-Dickinson) at admission were analyzed for hematogical and hemostatic parameters using standard clinical chemistry techniques. Complete blood counts including hemoglobin $(\mathrm{Hb})$, hematocrit (Hct), differential leukocyte and platelet (Plt) counts were performed using an automated Hematology Analyzer (Coulter $\mathrm{A}^{\mathrm{C}} \mathrm{T}$ diff 2, BeckmanCoulter, Hialeah, FL). Prothrombin time (PT, s) and activated partial thromboplastin time (aPTT, s) were measured by a Blood Coagulation System; International Normalized Ratio (INR) was calculated and reported by the same instrument and was used as a surrogate for PT to account for institutional variability in this marker.

Analyses of Plasma STF, sTM, and D-D Concentrations

Trisodium citrate, sodium heparin, and $\mathrm{K}_{2}$ EDTA anticoagulated blood samples were double centrifuged at $3000 \times g$ for $15 \mathrm{~min}$ to obtain platelet-poor plasma, which was stored in aliquots frozen at $-80^{\circ} \mathrm{C}$ until analysis at a later date. Plasma concentrations of sTF, sTM and D-D were analyzed using commercially available IMUBIND quantitative ELISA kits according to the manufacturer's instructions (American Diagnostica Inc, Stamford, CI). Briefly, plasma samples for determination of STF, sTM and D-D, respectively, were diluted 1:4, 1:5 and 1:50 with assay diluent; standards, samples, controls, and conjugate were incubated in precoated 96-well microplates. Any TF, TM and D-D present was sandwiched by the immobilized capture antibody and the enzyme-linked monoclonal antibody specific for these analytes. Following a wash to remove any unbound substances and/or antibody enzyme reagent, substrate solution was added to the wells allowing the colorometic reaction in proportion to the amount of STF, sTM and D-D bound. The color development was stopped and the absorbance read at $450 \mathrm{~nm}$ with wavelength correction in an automated microplate photometer (EL340, BIO-TEK Instruments, Winooski, VT); protein concentrations in each sample were calculated according to the standard curve of mean optical densities of duplicate incubations. The lowest analytical detection limits for $\mathrm{TF}, \mathrm{TM}$, and DD are $10 \mathrm{pg} / \mathrm{mL}, 0.3 \mathrm{ng} / \mathrm{mL}$ and $2 \mathrm{ng} /$ $\mathrm{mL}$, respectively.

\section{Assessment of Cell-Surface Adhesion and Degranulation}

\section{Molecules}

Simultaneous multi-colour direct staining and flow cytometric analysis of granuloctye and monocyte cell membrane adhesion and degranulation molecules were performed using 100- $\mu \mathrm{L}$ aliquots of fresh untreated whole blood. Samples were pipetted directly into $12 \times$ $75 \mathrm{~mm}$ polystyrene Falcon tubes and incubated with saturating concentrations of anti-CD14-APC, antiCD62L-FITC, anti-CD11b-PE, anti-CD66b-FITC, and anti-CD63-PE surface stains (BD Biosciences, San José, $\mathrm{CA})$ for $20 \mathrm{~min}$ at room temperature in the dark. Appropriate isotype-matched mAbs were added simultaneously to separate tubes as indicators of autofluorescence and non-specific antibody binding. Red blood cells were lysed by addition of $2 \mathrm{~mL}$ of $1 \times$ FACS $^{\text {Tw }}$ Lysing Solution for $10 \mathrm{~min}$, and centrifuged at $500 \times g 5$ $\min$ at $20^{\circ} \mathrm{C}$. The supernatant was washed with CellWASH $^{\mathrm{m}}$ and cell pellets resuspended in $400 \mu$ of $1 \%$ paraformaldehyde. Stained cell suspensions were acquired on a dual-laser FACSCalibur flow cytometer equipped with a 15-mW 488-nm air-cooled argon-ion laser 
supplemented with a 635-nm red diode laser (BD Biosciences). Instrument optical alignment, fluidics and dayto-day variability were monitored and adjusted using CaliBRITE $^{\oplus}$ fluorescence beads and FACSComp ${ }^{\circledR}$ software. For each sample, 103 events were collected as list mode data at a flow rate of 500 events/sec using CellQuest $^{\oplus}$ software, with a live gate set using a bivariate dotplot of anti-CD14 reactivity vs. SSC orthogonal lightscatter profile to allow the distinction of monocytes and PMNs. Isotype-matched control samples confirmed specificity and served to define quadrant markers for twodimensional dot-plot and fluorescence histogram analysis of positive and negative cell populations. Subsequent data analysis was performed using FlowJo software v.8.7 (Tree Star Inc., Ashland, OR). Results are expressed as the frequency of marker-positive events (\% positive cells) and as indirect measures of cell-surface antigen density using linear mean fluorescence intensity (MFI).

Determination of Serum Cytokines and Soluble Adhesion Molecule Concentrations

Blood samples collected into non-additive tubes were allowed to clot at room temperature and then centrifuged at $1000 \times g$ for $15 \mathrm{~min}$. The serum supernatants were separated into $0.5-\mathrm{mL}$ aliquots and frozen at $-80^{\circ} \mathrm{C}$ until batch analysis. Samples were subsequently thawed immediately before analyses and assayed in duplicate for circulating concentrations of TNF- $\alpha$, IL-10, SICAM-1, sVCAM-1, sE-selectin and sL-selectin, using commercially available quantitative ELISA kits according to the according to the manufacturer's protocol (Quantikine ${ }^{\oplus}$, R\&D systems Inc., Minneapolis MN). Absorbance was read at $450 \mathrm{~nm}$ with wavelength correction in an automated microplate photometer (EL340, BIO-TEK Instruments, Winooski, VT). Assay sensitivities for TNF- $\alpha$ and IL-10, corresponded to 0.12 and $0.5 \mathrm{pg} / \mathrm{mL}$, respectively; sICAM-1, sVCAM-1, sE-selectin and sL-selectin had detection limits 0.096, 0.6, 0.009 and $0.3 \mathrm{ng} / \mathrm{mL}$, respectively.

\section{Statistical Analysis}

Baseline demographic and clinical characteristics are expressed as the mean \pm standard deviation (SD). Data were assessed for normality and homogeneity of variance. Biomarker levels were treated as normally distributed continuous variables and expressed as mean \pm standard error of the mean (SEM). Univariate and multivariate techniques were used according to the type of data being tested: intergroup comparisons between dichotomous variables including demographic and clinical characteristics were performed using Student's $t$-test for continuous variables and $\chi^{2}$ test for categorical predictor variables; and the non-parametric Mann-Whitney $U$ test for continuous variables that were not normally distributed. Serial comparisons (time $\times$ treatment) of biomarkers between the treatment groups and control group were made using repeated measures ANOVA with post-hoc Bonferroni/Dunn testing. All analyses were two-tailed, with a $p$-value $<0.05$ indicating statistical significance.

\section{Results}

\section{Patient Demographics and Clinical Characteristics}

Table 1 summarizes demographic, injury and clinical characteristics of TBI patients enrolled into the substudy. The two fluid-treatment arms were well balanced with respect to age, GCS and other prognostic factors. There were no significant differences in presenting symptoms between the HSD and NS groups, with the exception of serum sodium and osmolality values, which were elevated in the HSD group.

\section{Circulating Leukocyte Counts}

Total and differential leukocyte counts are shown in Table 2. Relative to normal control values both groups of resuscitated TBI patients exhibited a significant posttraumatic leukocytosis (up to 3-fold higher) upon hospital admission, which persisted throughout the 48 -h observation period. Differential analyses revealed the

Table 2 Absolute leukocyte counts and relative subset proportions in TBI patients and controls.

\begin{tabular}{|c|c|c|c|c|c|c|c|c|c|}
\hline \multirow[t]{2}{*}{ Parameter } & \multirow[t]{2}{*}{ Control } & \multicolumn{4}{|c|}{$H S D$} & \multicolumn{4}{|c|}{ NS } \\
\hline & & $\operatorname{Adm}(\leq 3 \mathrm{~h})$ & $12 \mathrm{~h}$ & $24 \mathrm{~h}$ & $48 \mathrm{~h}$ & $\operatorname{Adm}(\leq 3 \mathrm{~h})$ & $12 \mathrm{~h}$ & $24 \mathrm{~h}$ & $48 \mathrm{~h}$ \\
\hline \multicolumn{10}{|l|}{ Leukocytes } \\
\hline Counts $^{1}$ & $5.7 \pm 0.1$ & $13.0 \pm 0.1^{*} \dagger$ & $11.3 \pm 0.3^{*}$ & $11.4 \pm 0.6^{*}$ & $10.4 \pm 0.2^{*}$ & $18.1 \pm 0.8^{*}$ & $12.3 \pm 0.6^{*}$ & $11.5 \pm 0.2^{*}$ & $11.4 \pm 0.5^{*}$ \\
\hline \multicolumn{10}{|l|}{ PMNs } \\
\hline Counts & $3.5 \pm 0.1$ & $10.8 \pm 0.3^{*} \dagger$ & $9.4 \pm 0.1^{*}$ & $9.6 \pm 0.2^{*}$ & $8.8 \pm 0.1^{*}$ & $15.8 \pm 0.4^{*}$ & $10.7 \pm 0.2^{*}$ & $9.7 \pm 0.1^{*}$ & $9.8 \pm 0.1^{*}$ \\
\hline$\%$ & $60.8 \pm 0.6$ & $82.4 \pm 0.6^{*}$ & $83.5 \pm 0.5^{*}$ & $83.5 \pm 0.8^{*}$ & $83.9 \pm 0.3^{*}$ & $86.5 \pm 1.0^{*}$ & $86.3 \pm 0.8^{*}$ & $84.1 \pm 0.6^{*}$ & $85.4 \pm 0.5^{*}$ \\
\hline \multicolumn{10}{|l|}{ Monocytes } \\
\hline Counts & $0.29 \pm 0.01$ & $0.54 \pm 0.02^{*} \dagger$ & $0.59 \pm 0.03^{*}$ & $0.52 \pm 0.02^{*}$ & $0.50 \pm 0.04^{*}$ & $0.74 \pm 0.04^{*}$ & $0.63 \pm 0.02^{*}$ & $0.57 \pm 0.03^{*}$ & $0.61 \pm 0.01^{*}$ \\
\hline$\%$ & $5.03 \pm 0.13$ & $4.37 \pm 0.14$ & $5.06 \pm 0.13$ & $4.64 \pm 0.11$ & $5.02 \pm 0.12$ & $4.14 \pm 0.11$ & $4.30 \pm 0.12$ & $5.27 \pm 0.13$ & $5.32 \pm 0.11$ \\
\hline
\end{tabular}

${ }^{1}$ Mean \pm standard error mean (SEM) cell concentrations $\left(\times 10^{9} / \mathrm{L}\right)$

${ }^{*} \mathrm{P}<0.05$ vs age-matched healthy controls; ${ }^{\dagger} \mathrm{P}<0.05$ vs time-matched NS-treated patients by ANOVA 
generalized leukocytosis was comprised mainly of a profound neutrophilia (increased proportion and number) and a lesser monocytosis. Compared to patients treated with NS, HSD resuscitated patients showed significantly lower total white cell, PMN and monocyte counts on hospital admission, although beyond this time-point values were not significantly different between treatment groups.

\section{Cell-Surface Adhesion and Degranulation Markers}

Figure 1(A-D) shows the post-resuscitation time course of spontaneous CD62L and CD11b cell-surface adhesion molecule expression on fresh peripheral blood PMNs and monocytes, obtained from TBI patients and healthy blood donors. A majority (90-100\%) of PMNs and monocytes from patients and controls were found to constitutively express CD62L and CD11b, with no significant temporal or intergroup differences in the proportion of cells bearing these receptors.
Significantly higher surface density as quantified as mean fluorescence intensity (MFI) of CD62L and CD11b was found on both PMNs and monocytes from NS-treated patients on admission in comparison with HSD patients and controls. Expression of CD62L by PMNs and monocytes were elevated in the NS group across all sample times relative to control, whereas HSD treatment significantly down-regulated CD62L expression at all time points. CD11b expression on PMNs and monocytes exhibited a biphasic response pattern in the NS group, with an initial upregulation observed on admission, followed by a second peak at 48-h post-resuscitation. By contrast, after HSD, CD11b levels remained relatively constant over time at levels approaching control values.

Figure 2(A-B) illustrates the temporal pattern of cell surface CD66b and CD63 degranulation marker expression on PMNs. Following resuscitation, both patient groups exhibited significant PMN degranulation, as
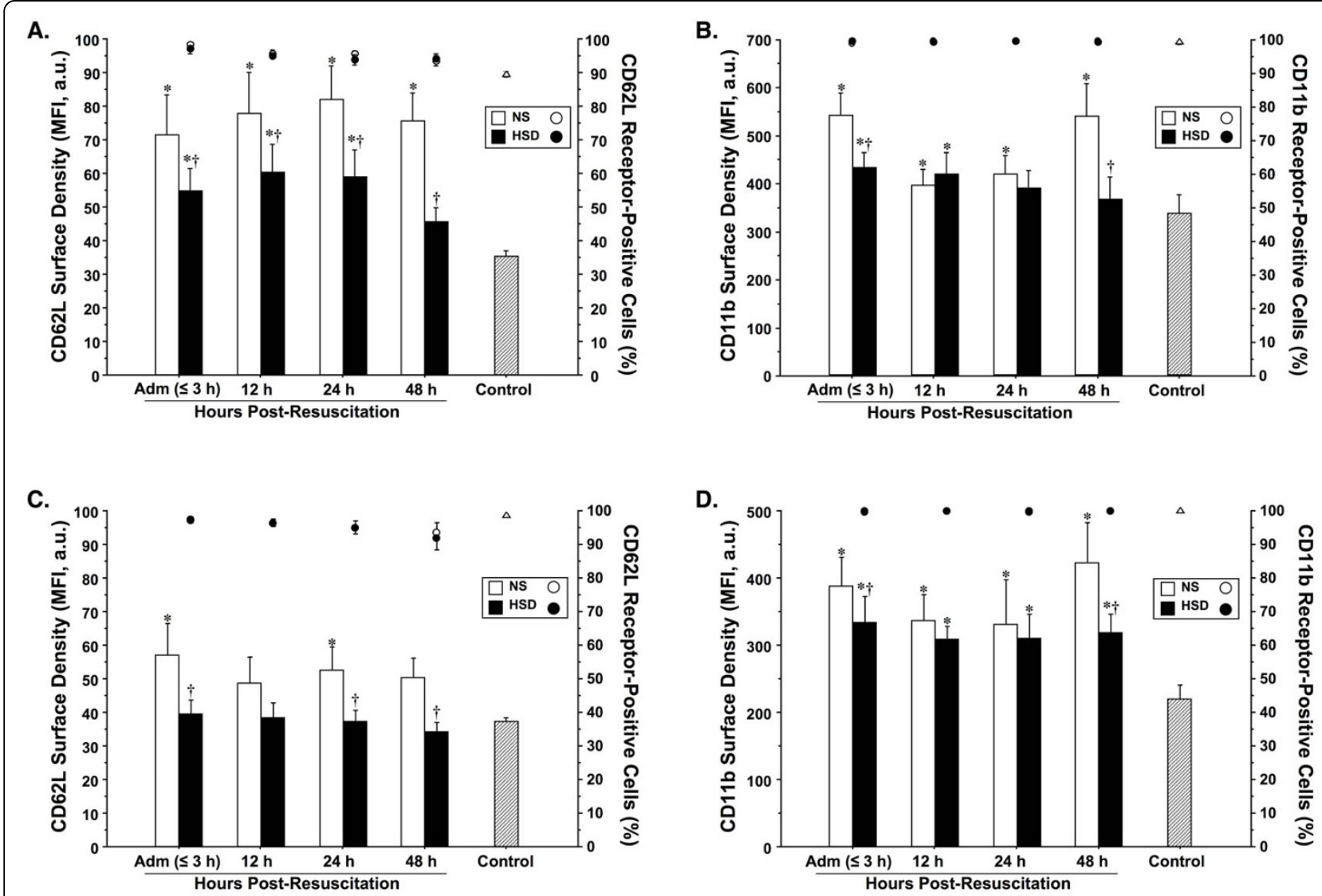

Figure 1 Cell-surface expression of L-selectin (CD62L) and $\beta_{2}$-integrin (CD11b) adhesion molecules on fresh peripheral blood monocytes (A-B) and polymorphonuclear neutrophils (PMNs; C-D) assessed by whole blood immunofluorescence flow cytometry. Results were expressed as mean fluorescence intensity (MFI \pm SEM; bars) in arbitrary units (a.u.) and the percentage of receptor-positive cells (circles), which correlate with antibody cell surface density. Blood was sampled serially from severe TBI patients resuscitated with normal saline (NS, $n=13$ ) vs hypertonic saline-dextran (HSD, $n=10$ ), upon hospital admission (Adm) and 12, 24, and 48-h post-resuscitation, and from healthy controls $(n=25)$. ${ }^{*} P<0.05$ vs age-matched healthy controls $(n=25) ;{ }^{\dagger} P<0.05$ vs time-matched NS-treated patients by ANOVA. 

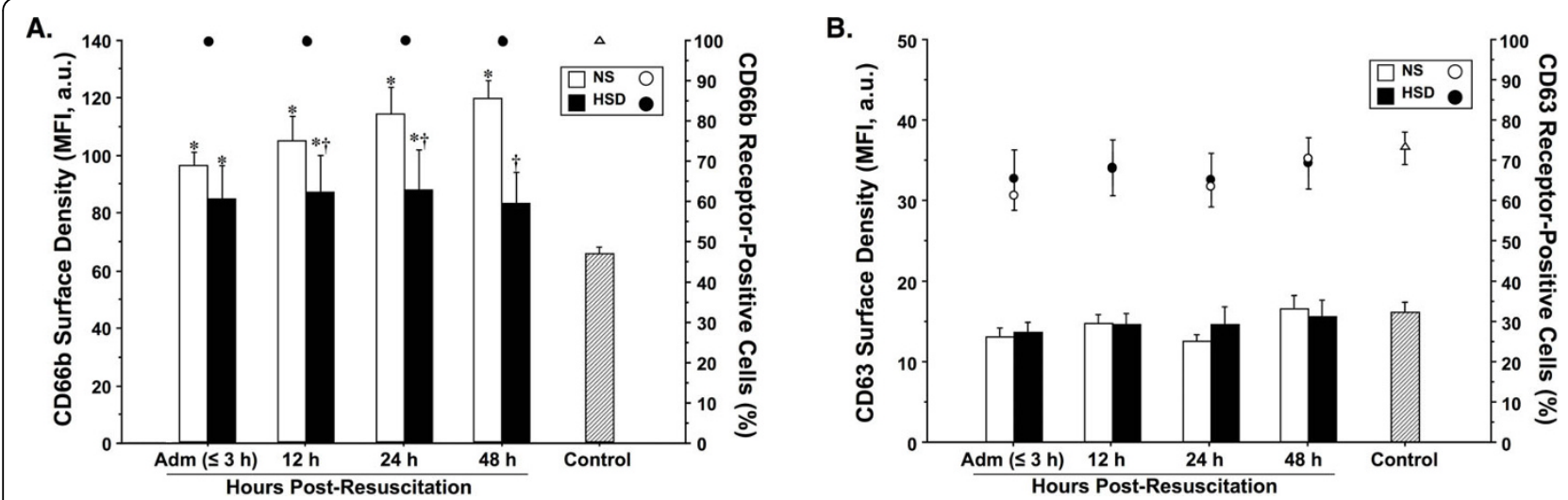

Figure 2 Cell-surface expression of specific (CD66b; A) and azurophilic (CD63; B) granular proteins on fresh polymorphonuclear neutrophils (PMNs), assessed by whole blood immunofluorescence flow cytometry. Results were expressed as mean linear fluorescence intensity (MFI \pm SEM; bars) in arbitrary units (a.u.) and the percentage of receptor-positive cells (circles). Blood was sampled serially from severe TBI patients resuscitated with normal saline (NS, $n=13$ ) vs hypertonic saline-dextran (HSD, $n=10$ ), upon hospital admission (Adm) and 12, 24, and 48-h post-resuscitation, and from healthy controls $(n=25){ }^{*} P<0.05$ vs age-matched healthy controls $(n=25)$; ${ }^{\dagger} P<0.05$ vs time-matched NS-treated patients by ANOVA.

evidenced by significantly higher surface expression of the specific granule marker CD66b in comparison to control. While the NS group showed progressively increasing levels of CD66b over time, HSD-treated patients displayed significantly lower CD66b protein density at all time points, which normalized by 48 -h. Neither resuscitation strategy was found to influence PMN expression of CD63-positive azurophilic granules, since the surface density did not differ between patients and healthy controls at any time-point.

\section{Soluble Adhesion Molecules}

Serum concentrations $(\mathrm{ng} / \mathrm{mL})$ of the panel of four soluble adhesion molecules assayed in patients and healthy controls are shown in Figure 3(A-D). These soluble markers displayed unique kinetics of appearance in serum with significant differences observed between treatment groups. Concentrations of sVCAM-1 were significantly elevated upon admission in the NS group as compared to HSD-resuscitated patients and controls. sVCAM-1 levels continued to rise in all patients over time with peak values attained 48-h post-resuscitation in HSD patients. Similarly, admission concentrations of sICAM-1 were higher in the NS group as compared to HSD and also reached a maximum at 48-h. Comparatively, sE-selectin time-course values were markedly elevated in the NS group compared to HSD and control values. In contrast to the other measured soluble adhesion molecules, sL-selectin concentrations were significantly lower on admission in all patients in comparison with healthy controls. In HSD-resuscitated patients sLselectin concentrations reached control values at 12 and $48 \mathrm{~h}$, but levels remained depressed in the NS group throughout the observation period.

\section{Serum Cytokine Concentrations}

As shown in Figure 4 (A-B), the serum concentrations (pg/ $\mathrm{mL}$ ) of proinflammatory TNF- $\alpha$ and antiinflammatory IL10 in resuscitated TBI patients were both markedly higher than those in control subjects. In particular, admission levels of TNF- $\alpha$ were 10-fold greater in NS-treated patients relative to control, and double those values observed in HSD patients. By comparison, TNF- $\alpha$ concentrations in HSD-treated patients did not show temporal variations but remained moderately above control values throughout the observation period. Peak serum IL-10 levels were 30 -fold higher in the NS group on admission relative to control, and twice as high as HSD patients at all time points. IL-10 declined progressively over the observation period in both groups but remained above normal at $48 \mathrm{~h}$.

\section{Plasma Coagulation Markers}

At the time of hospital admission, measurements of standard hemostasis indicators including INR, aPTT and platelet counts were within their normal ranges in both groups of TBI patients (Table 1); however, analyses of plasma concentrations of TF, TM, and D-D revealed pronounced differential effects of the two resuscitation strategies on patient coagulation profiles (Fig. 5A-C. Plasma concentrations of TF and D-D were significantly elevated in NS compared to HSD and control values. By contrast, HSD-resuscitated patients demonstrated significantly higher TM levels versus NS and control groups.

\section{Stratification of Biomarker Levels According to} Dichotomized GOS

GOS scores at the time of hospital discharge/death within 30-days were dichotomized as Poor versus Good (i.e., GOS score of 1-3 vs. GOS score of 4-5, respectively). After dichotomization of the mean admission values for cellular 

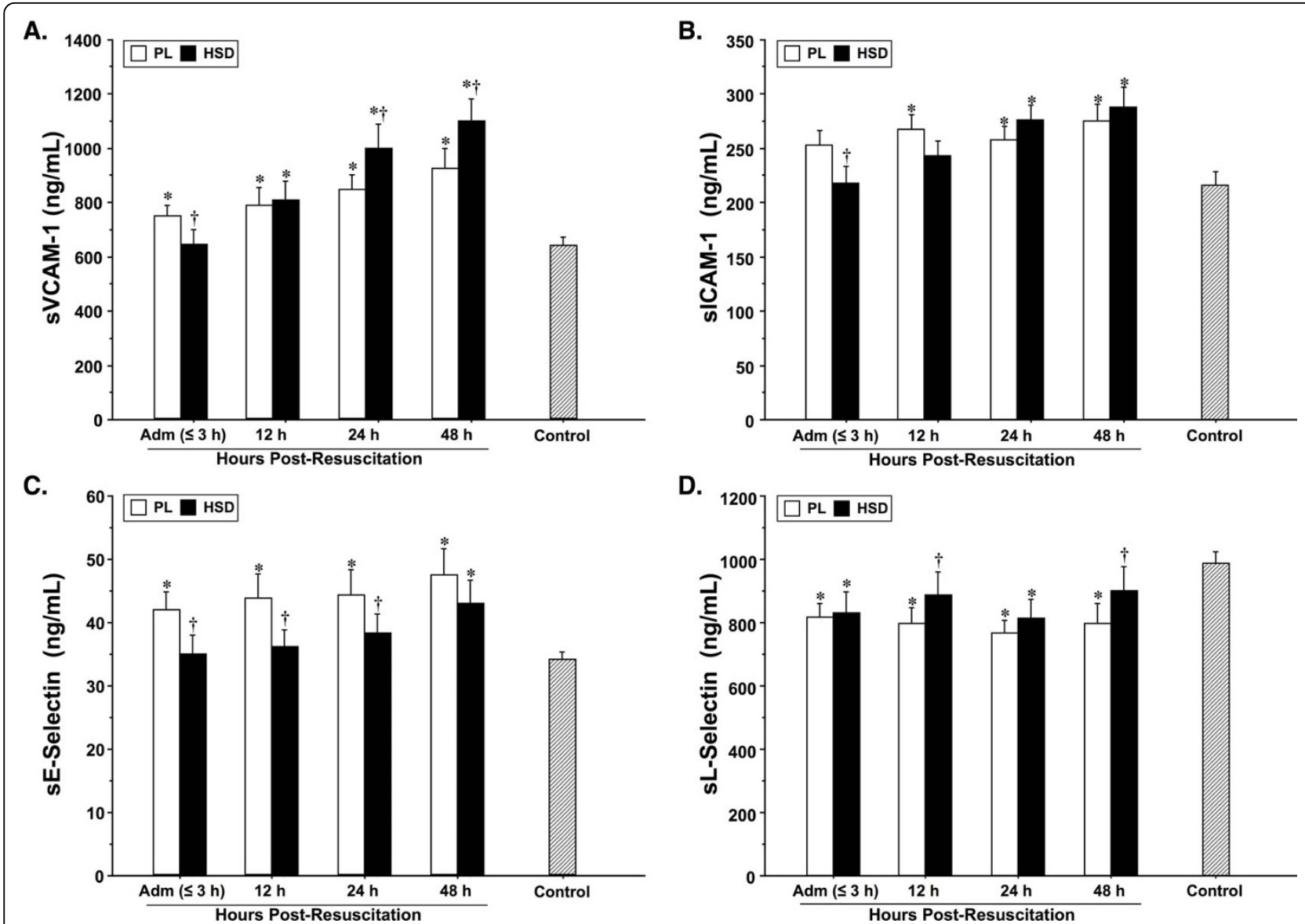

D.

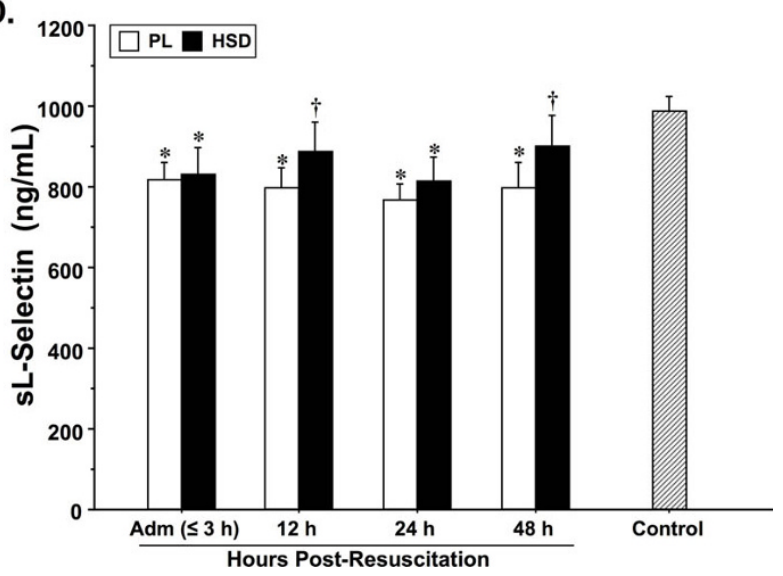

Figure 3 Serum concentrations (mean $\pm \mathrm{SEM}, \mathrm{ng} / \mathrm{mL}$ ) of soluble vascular cell adhesion molecule (sVCAM-1), intercellular adhesion molecule (sICAM-1), endothelial selectin (sE-selectin) and leukocyte selectin (L-selectin) in severe TBI patients resuscitated with normal saline (NS, $\boldsymbol{n}=\mathbf{3 5}$ ) or hypertonic saline-dextran (HSD, $\boldsymbol{n}=\mathbf{3 0}$ ) and healthy controls $(\boldsymbol{n}=\mathbf{2 5})$. Blood was sampled serially upon hospital admission (Adm) and 12, 24, and 48-h post-resuscitation. ${ }^{*} P<0.05$ vs age-matched healthy controls $(n=25){ }^{\dagger} P<0.05$ vs timematched NS-treated patients by ANOVA.

and soluble inflammatory and coagulation markers were further stratified according to fluid resuscitation groups (Table 3). Overall, the marker levels were significantly higher in patients who had a poor outcome or died than in those who survived with good outcome, irrespective of fluid treatment. Further subgroup analysis revealed that HSD-resuscitated patients showing a good neurological outcome according to dichotomized GOS 4-5 scores exhibited the lowest levels of cellular and soluble markers. Conversely, the highest levels of most markers were observed in NS-resuscitated patients with poor outcome GOS 1-3. The notable exceptions to this pattern were sLselectin and TM, which showed the lowest levels in those NS-treated patients with poor outcome.

\section{Discussion}

It is generally accepted that severe head injury causes a profound inflammatory response within the brain leading to breakdown of the BBB with peripheral leukocyte invasion $[5,48]$. There is also abundant evidence for reciprocal alterations between CNS and peripheral inflammatory cells/mediators, which initiate systemic inflammatory cascades $[4,49,50]$. Growing recognition of the limitations of isotonic fluids for cerebral resuscitation has led to the search for alternative osmotic agents aimed at restoring cerebral perfusion and reducing intracranial pressure, while simultaneously conferring neutroprotection. In this randomized controlled trial, we investigated the potential immunomodulatory effects of prehospital HSD resuscitation on the production and interplay of leukocyte and endothelial adhesion molecules, cytokines, and coagulation cofactors in severe TBI patients. Although there is extensive preclinical and clinical experience evaluating the use of hypertonic fluids for their superior volume-expanding properties following extra-cranial insults, little is known concerning the potential impact of 

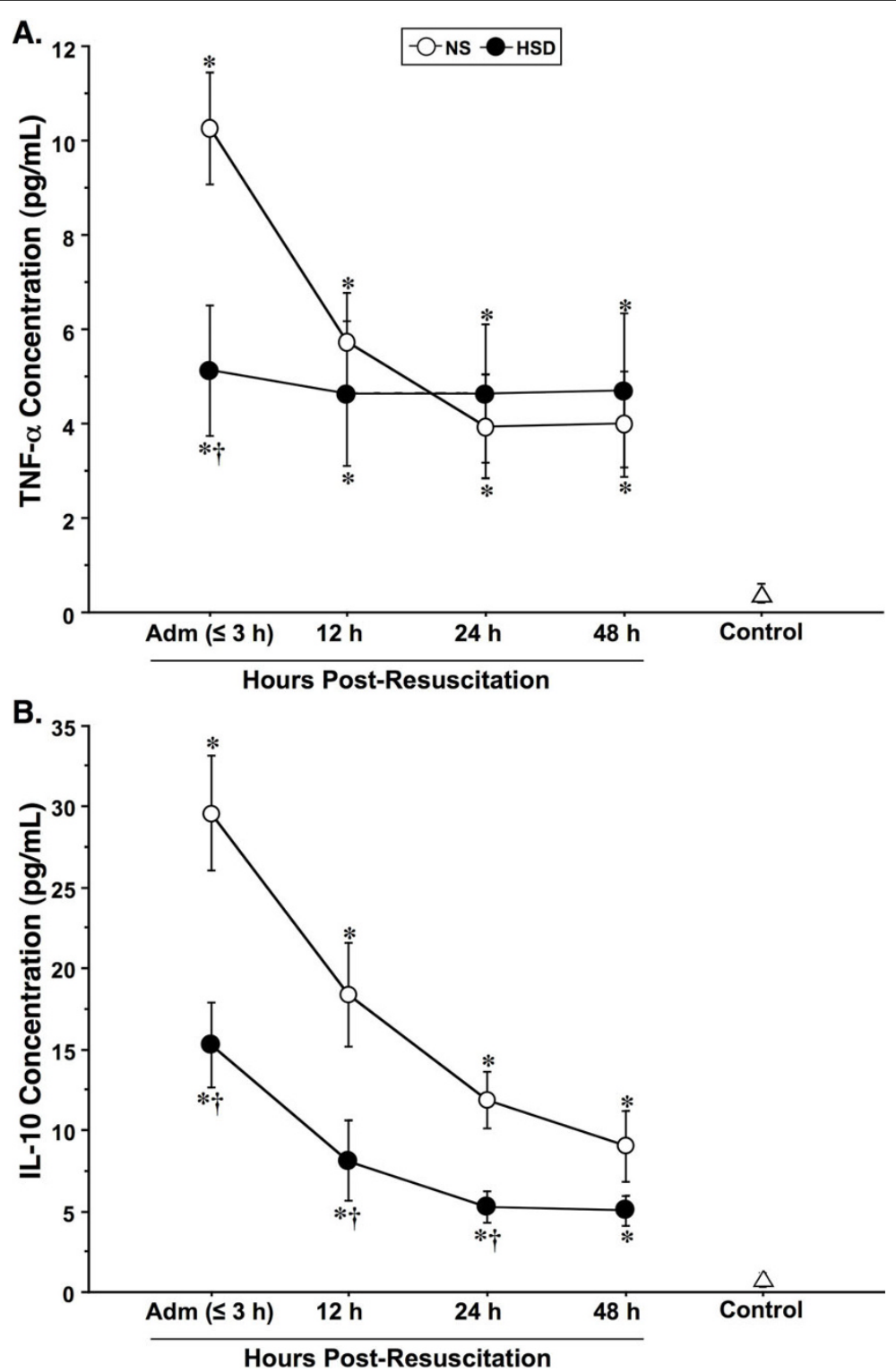

Figure 4 Kinetics of serum concentrations (mean \pm SEM, pg/mL) of pro- and anti-inflammatory cytokines TNF- $\alpha$ and IL-10 sampled serially in normal saline (NS, $n=35$ ) and hypertonic saline-dextran (HSD, $n=30$ ) resuscitated TBI patients, upon hospital admission (Adm), 12, 24, 48-h post-resuscitation. ${ }^{*} P<0.05$ vs age-matched healthy controls $(n=25) ;{ }^{\dagger} P<0.05$ vs time-matched NS-treated patients by ANOVA.

hyperosmolar therapy on acute immunoinflammatory response after isolated head injury [17,51]. HS/D has been shown to dampen posttraumatic hyperinflammatory responses and aberrant leukocyte-EC interactions, leading to reduced tissue cytotoxicity and end-organ damage in animal models of resuscitated hemorrhagic shock [52]; and recently the beneficial immunoregulatory properties of HS/D have also begun to translate into successful clinical trials of trauma patients $[12,14]$. However, to our knowledge, this is the first study to investigate the effects of HSD on the activation of cellular and molecular inflammatory/coagulation cascades initiated by TBI.

Leukocyte and endothelial cell activation/adhesion molecules

Posttraumatic leukocyte adherence and activation are critical mediators of the pathogenesis of host tissue injury. In this study, we assessed the role of specific leukocyte and endothelial-derived activation/adhesion molecules in resuscitated TBI patients. Our results provide evidence that the expression of cell-associated and soluble adhesion molecules in severe TBI is differentially 

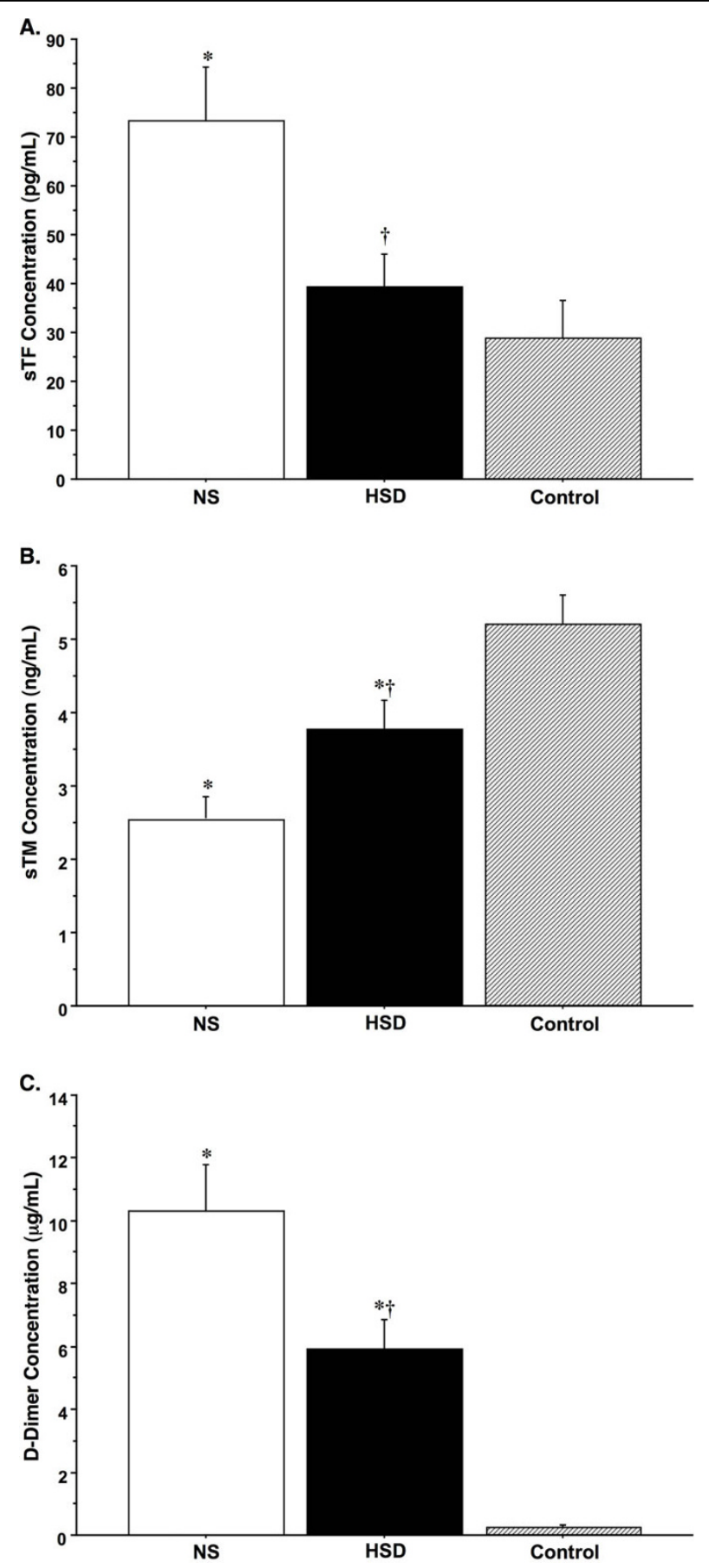

Figure 5 Plasma concentrations of tissue factor (sTF; A), thrombomodulin (sTM; B) and D-dimers (D-D; C) in TBI patients resuscitated with normal saline (NS, $\boldsymbol{n}=\mathbf{3 0}$ ) or hypertonic saline-dextran (HSD, $\boldsymbol{n}=\mathbf{2 5}$ ) at the time of hospital admission. ${ }^{*} P<0.05 \mathrm{vs}$ age-matched healthy controls $(n=25){ }^{\dagger} P<0.05$ vs time-matched NS-treated patients by ANOVA.

modulated depending on the type of fluid administered. After conventional crystalloid resuscitation, we found that relative to healthy controls, brain-injured patients exhibit extensive leukocyte mobilization, with significantly enhanced PMN and monocyte surface expression of L-selectin (CD62L) and $\beta_{2}$-integrin (CD11b) adhesion molecules, along with exocytosis of the specific granular protein $(\mathrm{CD} 66 \mathrm{~b})$. Along with increased expression of membrane-bound adhesion molecules, our analysis revealed that brain trauma caused elevated circulating levels of sE-selectin (sCD62E), sICAM-1 (sCD54) and sVCAM-1 (sCD106), but lower sL-selectin levels. A 
Table 3 Admission levels of inflammatory and coagulation biomarkers in patients according to dichotomized Glasgow Outcome Scores (GOS) and resuscitation treatment group.

\begin{tabular}{|c|c|c|c|c|}
\hline \multirow[t]{3}{*}{ Marker } & \multicolumn{4}{|c|}{ GOS Score } \\
\hline & \multicolumn{2}{|c|}{$H S D$} & \multicolumn{2}{|c|}{ NS } \\
\hline & Poor (1-3) & Good (4-5) & Poor (1-3) & Good (4-5) \\
\hline $\mathrm{CD}^{2} \mathrm{~L}, \mathrm{MFI}^{\S}$ & $48.5 \pm 4.6^{b}$ & $33.7 \pm 4.7^{\mathrm{a}, \mathrm{b}}$ & $58.5 \pm 5.9$ & $45.3 \pm 4.4^{a}$ \\
\hline $\mathrm{CD} 11 \mathrm{~b}, \mathrm{MFI}^{\S}$ & $443.3 \pm 58.7^{b}$ & $377.4 \pm 28.3^{a, b}$ & $539.3 \pm 91.8$ & $505.9 \pm 51.4$ \\
\hline $\mathrm{CD} 66 \mathrm{~b}, \mathrm{MFI}^{\S}$ & $124.4 \pm 28.4$ & $74.6 \pm 7.2^{a, b}$ & $135.1 \pm 17.9$ & $118.0 \pm 8.3^{a}$ \\
\hline sICAM-1, pg/mL & $228.3 \pm 28.3^{b}$ & $211.1 \pm 19.1^{b}$ & $254.4 \pm 13.5$ & $238.4 \pm 29.0$ \\
\hline sVCAM-1, pg/mL & $713.8 \pm 67.3^{b}$ & $574.2 \pm 70.0^{a, b}$ & $757.0 \pm 60.3$ & $741.1 \pm 54.8$ \\
\hline $\mathrm{sE}-$ Selectin, $\mathrm{pg} / \mathrm{mL}$ & $33.9 \pm 3.0^{b}$ & $31.1 \pm 4.0^{\mathrm{b}}$ & $45.2 \pm 3.8$ & $42.5 \pm 4.6$ \\
\hline sL-Selectin, $\mathrm{pg} / \mathrm{mL}$ & $849.2 \pm 64.7^{\mathrm{b}}$ & $875.2 \pm 87.3^{b}$ & $770.3 \pm 69.4$ & $870.1 \pm 60.0^{\circ}$ \\
\hline $\mathrm{TNF}-\alpha, \mathrm{pg} / \mathrm{mL}$ & $7.2 \pm 2.4^{b}$ & $4.9 \pm 1.7^{a, b}$ & $14.8 \pm 1.4$ & $6.9 \pm 1.3^{\mathrm{a}}$ \\
\hline IL-10, pg/mL & $19.6 \pm 6.3^{b}$ & $12.9 \pm 2.2^{a, b}$ & $30.3 \pm 4.9$ & $26.4 \pm 4.8^{\mathrm{a}}$ \\
\hline $\mathrm{TF}, \mathrm{pg} / \mathrm{mL}$ & $42.0 \pm 4.3^{b}$ & $39.5 \pm 12.6^{b}$ & $78.7 \pm 10.5$ & $65.8 \pm 15.9^{a}$ \\
\hline $\mathrm{TM}, \mathrm{ng} / \mathrm{mL}$ & $4.0 \pm 1.1^{b}$ & $3.6 \pm 1.3^{b}$ & $2.1 \pm 1.3$ & $2.8 \pm 1.1$ \\
\hline $\mathrm{D}-\mathrm{D}, \mu \mathrm{g} / \mathrm{mL}$ & $6.8 \pm 2.3^{b}$ & $6.4 \pm 1.2^{b}$ & $12.1 \pm 2.1$ & $7.6 \pm 1.9^{a}$ \\
\hline
\end{tabular}

Data are expressed as mean \pm standard error mean (SEM) for each marker.

$\S \mathrm{MFI}$, mean fluorescence intensity of surface antigen expression by neutrophils.

Abbreviations: NS, normal saline; HSD, hypertonic saline-dextran; GOS, Glasgow Outcome Scale score.

${ }^{\mathrm{a}} P<0.05$ vs GOS $1-3$; ${ }^{\mathrm{b}} P<0.05$ vs NS treated patients, by unpaired $t$-test.

major finding of the present trial was that HSD markedly attenuated TBI-induced changes in these vital cellassociated and soluble molecules compared to NS.

The prominent neutrophilia and monocytosis observed in TBI patients is a well-known feature of acute inflammation that is consistently reported in patients sustaining polytrauma and closed head-injury [53]. This reflects the sympathetic hormonal surge following severe tissue damage, which massively mobilizes leukocytes into the circulation from the marginal pool in the microvasculature. As observed in the current study [14], we previously reported that early resuscitation with HSD greatly reduces shock-associated leukocyte redistribution via inhibition of catecholamine release. The ability of HSD to attenuate the magnitude of post-injury leukocytosis is clinically relevant since elevated leukocyte counts on hospital admission reliably correlate with adverse neurological outcome and mortality risk after TBI [54].

Leukocyte infiltration of the CNS is a hallmark of neuroinflammation and a key mechanism contributing to the neuropathogenesis of secondary brain injury $[25,29]$. Cerebral edema, raised intracranial pressure and neurotoxicity are mediated, at least in part, by intracerebral accumulation of blood-borne leukocytes [55,56]. Trafficking of inflammatory cells from the bloodstream into the brain parenchyma depends upon the regulated expression of paired adhesion molecules on the surface of infiltrating leukocytes and cerebrovascular ECs $[29,30]$. Results of this study show that leukocytes from TBI patients resuscitated with NS display rapid induction of constitutively expressed CD62L and activation of $\mathrm{CD} 11 \mathrm{~b}$ with translocation to the cell membrane from intracellular secretory granules [31]. Consistent with these findings, studies in humans and animals demonstrate upregulated cell-surface CD62L and CD11b expression on leukocytes following polytrauma and isolated head-injury [57]. CD11b expression is also closely associated with CD66b (co-localized in specific granules) and upon ligation forms a macromolecular complex that induces clustering of $\beta_{2}$-integrins molecules, which potentiates avid binding to the endothelium with release of inflammatory mediators [58]. Importantly, the current results, showing that HSD prevents TBI-induced upregulation of leukocyte adhesion molecules, confirm previous in vitro human cellular studies [59,60], animal models $[13,61,62]$ and clinical trials $[12,14]$ of shock/ resuscitation, demonstrating that hypertonicity inhibits leukocyte adherence and activation via downregulation of selectins, integrins and immunoglobulin molecules, thus rendering cells incapable of rolling or adhering to the endothelium.

Experimental studies show widespread microvascular endothelial activation $[20,63]$ with upregulated adhesion molecule expression within 2-4 hours of neurological injury $[24,64]$. E-selectin is not normally present on non-inflamed cerebrovascular ECs, but is dramatically induced at the transcriptional level by inflammatory stimuli and upregulated expression mediates initial adherence of PMNs and monocytes to brain microvasculature after traumatic/ischemic insults [65]. Likewise, the constitutively low expression of ICAM-1 and VCAM-1 is rapidly upregulated on the cytokine-activated cerebrovascular ECs facilitating adhesion and transmigration of leukocytes into the CNS $[35,66,67]$. Immunohistochemical staining and microscopic analyses reveal early 
neutrophilic invasion of the brain parenchyma that peaks approximately $24 \mathrm{~h}$ after severe neurotrauma [68] and progresses to a predominance of monocyte/macrophage infiltrate by $72 \mathrm{~h}$ post-injury [69]. The temporal profile of cell recruitment in these earlier reports is consistent with the peak kinetics of CD62L and CD11b molecule expression we observed on blood PMNs and monocytes. Inappropriate sequestration of adherent leukocytes in postcapillary venules may aggravate neurovascular damage by further impairing cerebral blood flow [41] and by intracerebral release neurotoxic mediators [34].

The damaging role of infiltrating leukocytes in cerebral injury is substantiated by studies in which PMN depletion or administration of anti-adhesion antibodies [70] reversed impaired tissue perfusion, BBB dysfunction and reduced infarct size [30]. Furthermore, the extent of PMN accumulation is correlated with the degree of cerebral edema, injury severity, and poor outcome following TBI $[21,55]$. Although direct examination of cerebral leukocyte invasion was not possible in the present study, our recent findings in the same cohort of TBI patients showing marked elevations of serum S100B and NSE as indicators of brain damage after resuscitation with NS [44], are strongly suggestive of neuroinflammation, BBB impairment and cellular infiltration that may be ameliorated by HSD $[45,46]$. This assertion is also supported by intravital microscopy studies showing inhibition of leukocyte-EC interactions by hypertonic saline reduces microvascular permeability and tissue injury [13], and prevents BBB disruption allowing less intracerebral leukocyte sequestration in brain-injured animals compared to Ringers's [51,71].

Many adhesion molecules exist as both transmembrane proteins and biologically active soluble forms arising from proteolytic cleavage of the extracellular region of the membrane-bound molecule [42]. Increased levels of soluble adhesion molecules are reported in a variety of inflammatory conditions [72]. Although their physiological role(s) and clinical relevance is not fully resolved, it is generally accepted that elevated concentrations of these endothelial derivatives are liberated by activationinduced shedding, or arise as a result of direct vascular damage [73]. Our results showing enhanced serum concentrations of sE-selectin, sICAM-1 and sVCAM-1 are in accordance with the pattern of release of soluble selectins and immunoglobulin-type adhesion molecules characterized several experimental and clinical studies following brain injury $[24,74,75]$. High circulating concentrations of these molecules may serve as biomarkers for early diagnosis or prognosis of the development of the systemic inflammatory response syndrome, organ dysfunction and death after severe trauma or sepsis [76]. Similarly, increased sICAM-1 levels are reported to correlate with the extent of brain damage and breakdown of the BBB leading to poor outcomes after TBI [77]. Correspondingly, we found the highest levels of sEselectin, sICAM and SVCAM in association with poor neurological outcome (i.e., GOS 1-3) in NS resuscitated patients. Notably, the only published study assessing the effects of hypertonic saline on the circulating profile of soluble adhesion molecules found lower sICAM-1 levels in the CSF of severe trauma patients compared to lactated Ringer's [78].

Soluble adhesion molecules are suggested to serve a functional role, either by inhibiting ongoing immunoinflammatory responses by competitive binding or conversely by inducing a response in ligand-bearing cells [72]. For instance, elevated sE-selectin and SICAM-1 have been shown to activate leukocytes following neurological insult [24], whereas high sL-selectin levels are closely associated with decreased cellular interactions and reduced microvascular damage in critically injured patients [79]. Our findings of initially low sL-selectin levels in TBI patients are consistent with earlier studies showing an inverse relationship between sL-selectin concentrations and increased risk of organ failure or death following isolated head injuries [80]. Furthermore, the current results showing reduced surface expression of CD62L in HSD-treated patients, accompanied by corresponding increases in sL-selectin and better patient outcome, are in accordance with our previous findings in shock patients [14], and supports the theory that sLselectin shedding represents an endogenous regulatory mechanism to limit leukocyte-mediated injury [79].

\section{Inflammatory Cytokines}

Cytokines are critical mediators of neuroinflammation after TBI [5,23], regulating a wide-variety of cellular functions through autocrine and paracrine signaling networks that initiate and perpetuate inflammatory reactions [25]. Severe TBI is associated with rapid and substantial increases in the synthesis and release of various pro/antiinflammatory cytokines into CSF and blood [4]. Experimental models of closed-head injury [30] and clinical studies $[81,82]$ of TBI demonstrate early induction of TNF- $\alpha$ and IL- $1 \beta$ that peaks within 3-8 h of injury, followed by more sustained elevations of IL- 6 and IL-10 $[5,83]$. In this study, we focused on the prototypical pro- and antiinflammatory cytokines, TNF- $\alpha$ and IL-10, respectively, since large increases in both correlate with head injury severity and are indicative of poor clinical outcome [84]. Like earlier experimental and clinical studies, our findings indicate peak serum concentrations of TNF- $\alpha$ and IL-10 are detectable within the first $3 \mathrm{~h}$ of injury, but remain above control values for up to $48 \mathrm{~h}$. These cytokines are produced systemically and in high concentrations by resident microglia and infiltrating monocyte/macrophages in the acute phase of injury 
$[22,69]$. TNF- $\alpha$ induces capillary leak and edema formation [28], causing enhanced BBB permeability [29] and upregulated expression of adhesion molecules such as ICAM-1 and VCAM-1 on the surface of brain ECs and glial cells $[24,85]$, exacerbating intracerebral leukocyte infiltration and microcirculatory dysfunction [23,41]. Inflammatory cytokines also stimulate astrocyte reactivity, contributing to increased neuroinflammation and development of secondary injury following neurotrauma $[22,86]$. Correspondingly, recent in vivo and in vitro animal studies have shown that both central and peripheral osmotic stimulation with hypertonic saline attenuates the brain's innate immune response to injury, reducing microglial activation, astrocytosis, cytokine production and associated neural tissue loss $[15,16]$.

A remarkable finding of the current study was that HSD resuscitation halved the multifold increases in both TNF- $\alpha$ and IL-10 observed upon admission, but levels remained elevated for at least 48 -h in comparison to control values. Although, this is the first published report of the effects of HSD on cytokine production after TBI, our results are consistent with several earlier studies in humans and animals demonstrating a more balanced pro versus antiinflammatory cytokine profile following hypertonic resuscitation of hemorrhagic shock or sepsis [52]. Previous studies examining TNF- $\alpha$ gene transcription and protein expression in response to hypertonicity have consistently shown inhibition in animal models of posttraumatic shock/resuscitation $[87,88]$, in vitro exposure of human peripheral blood cells to hypertonic media [89-91], and ex vivo intracellular production by blood monocytes of resuscitated trauma patients [14]. Reports of endogenous IL-10 responses to hypertonicity are less consistent, exhibiting differential expression according to the dose administered, timing of treatment, type of injury, and tissue sample specificity. For example, we have demonstrated previously that inhospital resuscitation with HSD enhances spontaneous and LPS-stimulated IL-10 expression in blood monocytes of shock patients [14], which corresponds with increased production by tissue macrophages in rodent models of shock/resuscitation [92-94]. By contrast, our present findings show that pre-hospital HSD treatment of TBI induced a roughly $50 \%$ reduction in circulating IL-10 levels lasting for at least $24 \mathrm{~h}$, compared to NS. Similarly, clinically relevant doses of hypertonic saline in vitro were found to suppress IL-10 production in isolated LPS-stimulated human $\gamma \delta \mathrm{T}$ cells [91] and to decrease circulating IL-10 concentrations in rats sustaining shock/resuscitation [9].

The ability of HSD to attenuate, but not abrogate, cytokine responses after TBI may be critical in light of their proposed duality in mediating both protective and injurious roles [27]. It has been suggested that high levels of TNF- $\alpha$ exert deleterious effects on the progression of tissue damage during the acute stages of CNS injury, but play a reparative role at lower levels [2]. Also, the relatively low IL-10 concentrations seen in HSD patients are consistent with the premise that moderate sustained levels of this potent antiinflammatory/ immunosuppressive cytokine may be neuroprotective in early pathogenesis and subsequent termination of neuroinflammation, but detrimental at high levels [84,95]. In fact, it has been reported that up to $50 \%$ of isolated head-injury patients who survive an initial neurological insult subsequently die as a result of infection or nonneurological organ dysfunction [4]. Paralysis of cellmediated immunity following severe TBI, partially induced by enhanced sympathetic-mediated IL-10 release, appears to be responsible for systemic immunosuppression with increased susceptibility to infectious complications [96]. This is consistent with our data showing that NS treated patients with poor outcome according to GOS score also exhibit the highest levels of TNF- $\alpha$ and IL-10. These findings support the idea that HSD leads to a more homeostatic cytokine profile that may alter secondary injury processes without compromising neurologic recovery.

\section{Coagulation Molecules}

The posttraumatic inflammatory response impinges upon hemostatic regulatory mechanisms at multiple levels, including effects on procoagulant, anticoagulant and fibrinolytic systems [43]. Patients sustaining severe injury are at risk for coagulopathy due to concurrent hypothermia, blood loss, acidosis, and hemodilution [97]. Coagulation disorders are a frequent complication in patients with head injuries [26], which can be either hypercoagulable or hyperfibrinolytic and represent a powerful, independent predictor of prognosis [98]. TBIassociated hypercoagulability is associated with injurymediated disruption of the cerebrovasculature with exposure of abundant subendothelial TF to circulating factor VII initiating the extrinsic pathway [18]. Intravenous fluids contribute to dilutional coagulopathy and also show intrinsic effects on the hemostatic system [99], but relatively few studies refer to the functional consequences after hypertonic resuscitation [100] and none evaluating the effects of HS/D on coagulation in TBI patients. Available in vitro and in vivo laboratory data suggest that hypertonic fluids exerts dose-dependent anticoagulant activity in animals or in serially diluted normal human plasma, as determined by routine clot-based assays and thromboelastography [101-104]. These studies provide evidence of direct anticoagulant effects of hypertonicity on plasma clotting factors and platelet activity and/or through interaction with inflammatory pathways $[104,105]$. 
Patients in the current study did not exhibit coagulopathy, as defined by standard clinical tests (i.e., INR > 1.3 or aPTT $>34 \mathrm{~s}$ ), but significant differences were evident in circulating concentrations of coagulation cofactors between treatment groups. Based on the measured plasma STF, sTM and D-D levels, our results show that compared to control, NS-resuscitated TBI patients exhibit activation of coagulation with concurrent down-regulation of anticoagulant systems and fibrinolysis. Furthermore, a key finding of this study was that HSD reduced TBI-induced increases in STF and D-D levels by half, while maintaining sTM levels near control values. This suggests that hypertonic resuscitation may act to improve coagulofibrinolytic balance after TBI. Previous studies have shown liberation of a soluble TF from both vascular and extravascular sources following traumatic injury [36]. sTF is released into the circulation within hours of head injury [106], and inducible TF expression is rapidly upregulated on the surface of circulating monocytes after injury [38]. Although the source of the early increase in STF is not clear, it likely the result of cleavage from TF-bearing monocytes and/ or release from dysfunctional brain ECs in response to inflammatory cytokines $[18,39]$. Elevated systemic and intracerebral TNF- $\alpha$ release after TBI has been shown to have procoagulant effects, stimulating synthesis and release of sTF while suppressing cell-surface TM levels and the protein C pathway [35]. Normally, TM acts to control hemostasis through high-affinity binding of thrombin, which activates anticoagulant and antiinflammatory protein C pathways [40,97]. Elevated levels of sTM, as in the current study, are thought to reflect increased surface expression and shedding of transmembrane TM, which plays a role in regulating not only hemostasis, but also inflammation, thus providing a close link between these processes [40]. Although the biological relevance of changes in sTM in brain injury is not well characterized [35], emerging data from clinical and animal studies suggest that increases in endogenous STM or exogenous administration of TM may have potent antithrombotic/antiinflammatory properties in inflammatory disease [107].

In conclusion, this study of severe head injury patients demonstrates that prehospital treatment with HSD attenuates inflammatory and coagulation cascades by modulating leukocyte and endothelial cell adhesion/activation molecule expression, pro/antiinflammatory cytokine release and pro/anticoagulant responses. These findings provide direct evidence that initial resuscitation with HSD imparts functional changes to inflammatory cells after TBI, which may inhibit the capacity for infiltration of damaged CNS tissues, thereby reducing potential neuroinflammatory events associated with secondary brain injury. Our results also suggest that by downregulating inflammatory mediator production, HSD may help prevent procoagulant TF-dependent derangements of hemostasis and fibrinolysis, which may otherwise contribute to intravascular thrombosis.

\section{Abbreviations}

ANOVA: analysis of variance; BBB: blood-brain barrier; CNS: central nervous system; EC: endothelial cell; CSF: cerebrospinal fluid; D-D: d-dimers; HS/D: hypertonic saline with or without dextran; HSD: 7.5\% hypertonic saline plus 6\% dextran-70; ICAM-1: intercellular adhesion molecule-1; IL: interleukin; LPS: lipopolysaccharide; INR: international normalized ratio; MBP: myelin basic protein; MFI: mean fluorescence intensity; NSE: neuron specific enolase; PMN polymorphonuclear neutrophil; PBS: phosphate-buffered saline; PT: prothrombin time; aPTT: activated partial thromboplastin time; TBI: traumatic brain injury; TF: tissue factor; TM: thrombomodulin; TNF- $\alpha$ : tumor necrosis factor alpha; VCAM-1: vascular cell adhesion molecule-1.

\section{Acknowledgements}

The authors are indebted to Sheila Petrongolo, Bartolomeu Nascimento and Maria Shiu for their skillful technical assistance; the paramedic providers employed by Ornge (formerly Ontario Air Ambulance) and Toronto Emergency Medical Services (members CUPE 416) who randomized these patients under conditions of adversity in the prehospital setting; Merita Simitciu and Tyrone Perreira (Rescu) for their study coordination and oversight. This study was funded by Defence Research \& Development Canada.

\section{Author details}

'Defence Research and Development Canada (DRDC), Toronto, Canada. ${ }^{2}$ Graduate Program in Kinesiology and Health Science, York University, Toronto, Canada. ${ }^{3}$ Department of Laboratory Medicine and Pathobiology, Faculty of Medicine, University of Toronto, Canada. ${ }^{4}$ Brain Injury Laboratory, Cara Phelan Centre for Trauma Research Keenan Research Centre, Li Ka Shing Knowledge Institute, St Michael's Hospital, University of Toronto, Toronto, Ontario, Canada. ${ }^{5}$ Critical Care Medicine, St Michael's Hospital, University of Toronto, Ontario, Canada. ${ }^{6}$ Rescu, Keenan Research Centre, Li Ka Shing Knowledge Institute, St Michael's Hospital, University of Toronto, Toronto, Ontario, Canada. ${ }^{7}$ Department of Surgery and Critical Care Medicine, Sunnybrook Health Sciences Centre, Toronto, Ontario, Canada.

\section{Authors' contributions}

Study Concept and Design: SBR, SGR, PNS, AJB, LJM. Study Implementation and Coordination: LJM, SBR, SGR, AJB. Data Collection and Analysis: SGR, NTC. Drafting Manuscript: SGR, NTC, SBR, SS. Revision of Manuscript: SGR, SBR, PNS, AJB, NTC, LJM, SC. All authors read and approved the final manuscript.

\section{Competing interests}

The authors declare that they have no competing interests.

\section{Received: 20 November 2009}

Accepted: 18 January 2010 Published: 18 January 2010

\section{References}

1. Cernak I, Noble-Haeusslein LJ: Traumatic brain injury: an overview of pathobiology with emphasis on military populations. J Cereb Blood Flow Metab 2009.

2. Schmidt OI, Infanger M, Heyde CE, Ertel W, Stahel PF: The role of neuroinflammation in traumatic brain injury. Eur J Trauma 2004, 3:135149.

3. Stahel PF, Smith WR, Moore EE: Hypoxia and hypotension, the "lethal duo" in traumatic brain injury: implications for prehospital care. Intensive Care Med 2008, 34:402-404.

4. Lu J, Goh SJ, Tng PY, Deng YY, Ling EA, Moochhala S: Systemic inflammatory response following acute traumatic brain injury. Front Biosci 2009, 14:3795-3813

5. Morganti-Kossmann MC, Satgunaseelan L, Bye N, Kossmann T: Modulation of immune response by head injury. Injury 2007, 38:1392-1400. 
6. Hammell CL, Henning JD: Prehospital management of severe traumatic brain injury. BMJ 2009, 338:b1683.

7. Adamides AA, Winter CD, Lewis PM, Cooper DJ, Kossmann T, Rosenfeld JV: Current controversies in the management of patients with severe traumatic brain injury. ANZ J Surg 2006, 76:163-174.

8. Menon DK: Unique challenges in clinical trials in traumatic brain injury. Crit Care Med 2009, 37:S129-135.

9. Boomer L, Jones W, Davis B, Williams S, Barber A: Optimal Fluid Resuscitation: Timing and Composition of Intravenous Fluids. Surg Infect (Larchmt) 2009, 10:379-87.

10. Oddo M, Levine JM, Frangos S, Carrera E, Maloney-Wilensky E, Pascual JL, Kofke WA, Mayer SA, LeRoux PD: Effect of mannitol and hypertonic saline on cerebral oxygenation in patients with severe traumatic brain injury and refractory intracranial hypertension. I Neurol Neurosurg Psychiatry 2009, 80:916-920.

11. Strandvik GF: Hypertonic saline in critical care: a review of the literature and guidelines for use in hypotensive states and raised intracranial pressure. Anaesthesia 2009, 64:990-1003.

12. Bulger EM, Jurkovich GJ, Nathens AB, Copass MK, Hanson S, Cooper C, Liu PY, Neff M, Awan AB, Warner K, Maier RV: Hypertonic resuscitation of hypovolemic shock after blunt trauma: a randomized controlled trial. Arch Surg 2008, 143:139-148, discussion 149

13. Pascual JL, Ferri LE, Seely AJ, Campisi G, Chaudhury P, Giannias B, Evans DC, Razek T, Michel RP, Christou NV: Hypertonic saline resuscitation of hemorrhagic shock diminishes neutrophil rolling and adherence to endothelium and reduces in vivo vascular leakage. Ann Surg 2002, 236:634-642.

14. Rizoli SB, Rhind SG, Shek PN, Inaba K, Filips D, Tien H, Brenneman F, Rotstein $\mathrm{O}$ : The immunomodulatory effects of hypertonic saline resuscitation in patients sustaining traumatic hemorrhagic shock: a randomized, controlled, double-blinded trial. Ann Surg 2006, 243:47-57.

15. Summy-Long JY, Hu S: Peripheral osmotic stimulation inhibits the brain's innate immune response to microdialysis of acidic perfusion fluid adjacent to supraoptic nucleus. Am J Physiol Regul Integr Comp Physiol 2009, 297:R1532-1545.

16. Elliott MB, Jallo JJ, Barbe MF, Tuma RF: Hypertonic saline attenuates tissue loss and astrocyte hypertrophy in a model of traumatic brain injury. Brain Res 2009, 1305:183-91, Epub 2009 Oct 3.

17. Sell SL, Avila MA, Yu G, Vergara L, Prough DS, Grady JJ, DeWitt DS: Hypertonic resuscitation improves neuronal and behavioral outcomes after traumatic brain injury plus hemorrhage. Anesthesiology 2008, 108:873-881.

18. Stein SC, Smith DH: Coagulopathy in traumatic brain injury. Neurocrit Care 2004, 1:479-488

19. Lehnardt S: Innate immunity and neuroinflammation in the CNS: The role of microglia in Toll-like receptor-mediated neuronal injury. Glia 2009, 58:253-63.

20. Balabanov R, Goldman H, Murphy S, Pellizon G, Owen C, Rafols J, DoreDuffy P: Endothelial cell activation following moderate traumatic brain injury. Neurol Res 2001, 23:175-182.

21. Bednar MM, Gross CE, Howard DB, Lynn M: Neutrophil activation in acute human central nervous system injury. Neurol Res 1997, 19:588-592.

22. Carson MJ, Thrash JC, Walter B: The cellular response in neuroinflammation: The role of leukocytes, microglia and astrocytes in neuronal death and survival. Clin Neurosci Res 2006, 6:237-245.

23. Kadhim HJ, Duchateau J, Sebire G: Cytokines and brain injury: invited review. J Intensive Care Med 2008, 23:236-249.

24. Lee SJ, Benveniste EN: Adhesion molecule expression and regulation on cells of the central nervous system. J Neuroimmunol 1999, 98:77-88.

25. Soriano SG, Piva S: Central nervous system inflammation. Eur J Anaesthesiol Suppl 2008, 42:154-159.

26. Harhangi BS, Kompanje EJ, Leebeek FW, Maas Al: Coagulation disorders after traumatic brain injury. Acta Neurochir (Wien) 2008, 150:165-175, discussion 175

27. Sriram K, O'Callaghan JP: Divergent roles for tumor necrosis factor-alpha in the brain. I Neuroimmune Pharmacol 2007, 2:140-153.

28. Feuerstein GZ, Liu T, Barone FC: Cytokines, inflammation, and brain injury: role of tumor necrosis factor-alpha. Cerebrovasc Brain Metab Rev 1994, 6:341-360.

29. Engelhardt B: Immune cell entry into the central nervous system: involvement of adhesion molecules and chemokines. J Neurol Sci 2008, 274:23-26.
30. McKeating $E G$, Andrews PJ: Cytokines and adhesion molecules in acute brain injury. Br J Anaesth 1998, 80:77-84.

31. Langer HF, Chavakis T: Leukocyte-endothelial interactions in inflammation. J Cell Mol Med 2009, 13:1211-1220.

32. Scholz M, Cinatl J, Schadel-Hopfner M, Windolf J: Neutrophils and the blood-brain barrier dysfunction after trauma. Med Res Rev 2007, 27:401416.

33. Lacy P, Eitzen G: Control of granule exocytosis in neutrophils. Front Biosci 2008, 13:5559-5570.

34. Nguyen HX, O'Barr TJ, Anderson AJ: Polymorphonuclear leukocytes promote neurotoxicity through release of matrix metalloproteinases, reactive oxygen species, and TNF-alpha. J Neurochem 2007, 102:900-912.

35. Yokota H, Naoe Y, Nakabayashi M, Unemoto K, Kushimoto S, Kurokawa A, Node $Y$, Yamamoto Y: Cerebral endothelial injury in severe head injury: the significance of measurements of serum thrombomodulin and the von Willebrand factor. J Neurotrauma 2002, 19:1007-1015.

36. Levi M, Poll van der T, ten Cate H: Tissue factor in infection and severe inflammation. Semin Thromb Hemost 2006, 32:33-39.

37. Saggar V, Mittal RS, Vyas MC: Hemostatic Abnormalities in Patients with Closed Head Injuries and Their Role in Predicting Early Mortality. $J$ Neurotrauma 2009, 26:1665-8.

38. Gando S: Tissue factor in trauma and organ dysfunction. Semin Thromb Hemost 2006, 32:48-53.

39. Szotowski B, Antoniak S, Poller W, Schultheiss HP, Rauch U: Procoagulant soluble tissue factor is released from endothelial cells in response to inflammatory cytokines. Circ Res 2005, 96:1233-1239.

40. Koutsi A, Papapanagiotou A, Papavassiliou AG: Thrombomodulin: from haemostasis to inflammation. Int J Biochem Cell Biol 2008, 40:1669-1673.

41. Fisher M: Injuries to the vascular endothelium: vascular wall and endothelial dysfunction. Rev Neurol Dis 2008, 5(Suppl 1):S4-11.

42. Gearing AJ, Hemingway I, Pigott R, Hughes J, Rees AJ, Cashman SJ: Soluble forms of vascular adhesion molecules, E-selectin, ICAM-1, and VCAM-1: pathological significance. Ann N Y Acad Sci 1992, 667:324-331.

43. Esmon $C \mathrm{~T}$ : Crosstalk between inflammation and thrombosis. Maturitas 2008, 61:122-131.

44. Baker AJ, Rhind SG, Morrison LJ, Black S, Crnko NT, Shek PN, Rizoli SB: Resuscitation with hypertonic saline-dextran reduces serum biomarker levels and correlates with outcome in severe traumatic brain injury patients. J Neurotrauma 2009, 26:1227-1240

45. Blyth BJ, Farhavar A, Gee C, Hawthorn B, He H, Nayak A, Stocklein V, Bazarian JJ: Validation of serum markers for blood-brain barrier disruption in traumatic brain injury. J Neurotrauma 2009, 26:1497-1507.

46. Vajtr D, Benada O, Kukacka J, Prusa R, Houstava L, Toupalik P, Kizek R: Correlation of ultrastructural changes of endothelial cells and astrocytes occurring during blood brain barrier damage after traumatic brain injury with biochemical markers of BBB leakage and inflammatory response. Physiol Res 2009, 58:263-268.

47. Morrison LJ, Rizoli SB, Schwartz B, Rhind SG, Simitciu M, Perreira T, Macdonald R, Trompeo A, Stuss DT, Black SE, et al: The Toronto prehospital hypertonic resuscitation-head injury and multi organ dysfunction trial (TOPHR HIT)-methods and data collection tools. Trials 2009, 10:105.

48. Schmidt OI, Heyde CE, Ertel W, Stahel PF: Closed head injury-an inflammatory disease?. Brain Res Brain Res Rev 2005, 48:388-399.

49. Catania A, Lonati C, Sordi A, Gatti S: Detrimental consequences of brain injury on peripheral cells. Brain Behav Immun 2009, 23:877-84, Epub 2009 Apr 24.

50. Lim HB, Smith M: Systemic complications after head injury: a clinical review. Anaesthesia 2007, 62:474-482.

51. Hartl R, Medary MB, Ruge M, Arfors KE, Ghahremani F, Ghajar J: Hypertonic/ hyperoncotic saline attenuates microcirculatory disturbances after traumatic brain injury. J Trauma 1997, 42:S41-47.

52. Scarpelini S, Rhind SG, Tien H, Spencer Netto AC, Leung KK, Rizoli SB: Effects of hypertonic saline on the development of acute lung injury following traumatic shock. Journal of Organ Dysfunction 2008, 4:99-105.

53. Santucci CA, Purcell TB, Mejia C: Leukocytosis as a predictor of severe injury in blunt trauma. West J Emerg Med 2008, 9:81-85.

54. Rovlias A, Kotsou S: The blood leukocyte count and its prognostic significance in severe head injury. Surg Neurol 2001, 55:190-196.

55. Schoettle RJ, Kochanek PM, Magargee MJ, Uhl MW, Nemoto EM: Early polymorphonuclear leukocyte accumulation correlates with the 
development of posttraumatic cerebral edema in rats. J Neurotrauma 1990, 7:207-217.

56. Zhuang J, Shackford SR, Schmoker JD, Anderson ML: The association of leukocytes with secondary brain injury. J Trauma 1993, 35:415-422.

57. Maekawa K, Futami S, Nishida M, Terada T, Inagawa H, Suzuki S, Ono K: Effects of trauma and sepsis on soluble L-selectin and cell surface expression of L-selectin and CD11b. J Trauma 1998, 44:460-468.

58. Ruchaud-Sparagano MH, Stocks SC, Turley H, Dransfield I: Activation of neutrophil function via CD66: differential effects upon beta 2 integrin mediated adhesion. Br J Haematol 1997, 98:612-620

59. Rhee P, Wang D, Ruff P, Austin B, DeBraux S, Wolcott K, Burris D, Ling G, Sun L: Human neutrophil activation and increased adhesion by various resuscitation fluids. Crit Care Med 2000, 28:74-78.

60. Thiel M, Buessecker F, Eberhardt K, Chouker A, Setzer F, Kreimeier U, Arfors KE, Peter K, Messmer K: Effects of hypertonic saline on expression of human polymorphonuclear leukocyte adhesion molecules. I Leukoc Biol 2001, 70:261-273.

61. Alam HB, Sun L, Ruff P, Austin B, Burris D, Rhee P: E- and P-selectin expression depends on the resuscitation fluid used in hemorrhaged rats. J Surg Res 2000, 94:145-152.

62. Angle N, Hoyt DB, Cabello-Passini R, Herdon-Remelius C, Loomis W, Junger WG: Hypertonic saline resuscitation reduces neutrophil margination by suppressing neutrophil $\mathrm{L}$ selectin expression. I Trauma 1998, 45:7-12, discussion 12-13.

63. Sibson NR, Blamire AM, Bernades-Silva M, Laurent S, Boutry S, Muller RN, Styles P, Anthony DC: MRI detection of early endothelial activation in brain inflammation. Magn Reson Med 2004, 51:248-252.

64. Carlos TM, Clark RS, Franicola-Higgins D, Schiding JK, Kochanek PM: Expression of endothelial adhesion molecules and recruitment of neutrophils after traumatic brain injury in rats. J Leukoc Biol 1997, 61:279285.

65. Bernardes-Silva M, Anthony DC, Issekutz AC, Perry VH: Recruitment of neutrophils across the blood-brain barrier: the role of $\mathrm{E}$ - and P-selectins. J Cereb Blood Flow Metab 2001, 21:1115-1124.

66. Hess DC, Bhutwala T, Sheppard JC, Zhao W, Smith J: ICAM-1 expression on human brain microvascular endothelial cells. Neurosci Lett 1994, 168:201204.

67. Stanimirovic DB, Wong J, Shapiro A, Durkin JP: Increase in surface expression of ICAM-1, VCAM-1 and E-selectin in human cerebromicrovascular endothelial cells subjected to ischemia-like insults. Acta Neurochir Suppl 1997, 70:12-16.

68. Royo NC, Wahl F, Stutzmann JM: Kinetics of polymorphonuclear neutrophil infiltration after a traumatic brain injury in rat. Neuroreport 1999, 10:1363-1367.

69. D'Mello C, Le T, Swain MG: Cerebral microglia recruit monocytes into the brain in response to tumor necrosis factor alpha signaling during peripheral organ inflammation. J Neurosci 2009, 29:2089-2102.

70. Weaver KD, Branch CA, Hernandez L, Miller CH, Quattrocchi KB: Effect of leukocyte-endothelial adhesion antagonism on neutrophil migration and neurologic outcome after cortical trauma. J Trauma 2000, 48:1081-1090.

71. Barone M, Jimenez DF, Huxley VH, Yang XF: Cerebral vascular response to hypertonic fluid resuscitation in thermal injury. Acta Neurochir Suppl 1997, 70:265-266.

72. Giddings JC: Soluble adhesion molecules in inflammatory and vascular diseases. Biochem Soc Trans 2005, 33:406-408.

73. Mousa SA: Cell adhesion molecules potential therapeutic \& diagnostic implications. Mol Biotechnol 2008, 38:33-40.

74. McKeating EG, Andrews PJ, Mascia L: The relationship of soluble adhesion molecule concentrations in systemic and jugular venous serum to injury severity and outcome after traumatic brain injury. Anesth Analg 1998, 86:759-765.

75. Siemiatkowski A, Rogowski F, Wereszczynska-Siemiatkowska U, Malinowska L, Borkowski J: Soluble selectin profiles associated with severe trauma. Arch Immunol Ther Exp (Warsz) 2001, 49:317-324.

76. Cowley HC, Heney D, Gearing AJ, Hemingway I, Webster NR: Increased circulating adhesion molecule concentrations in patients with the systemic inflammatory response syndrome: a prospective cohort study. Crit Care Med 1994, 22:651-657.

77. McKeating EG, Andrews PJ, Mascia L: Leukocyte adhesion molecule profiles and outcome after traumatic brain injury. Acta Neurochir Suppl 1998, 71:200-202.
78. Bing $M$, Zheng-lu $H$, Hui $C$, Xian D, Jian H: Variations of $p 38$ MAPK and sICAM-1 with therapeutic effect of different resuscitation fluids on severe traumatic patients. Chin J Traumatol 2007, 10:263-268.

79. Ferri $L E$, Chia S, Benay C, Giannias B, Christou NV: L-selectin shedding in sepsis limits leukocyte mediated microvascular injury at remote sites. Surgery 2009, 145:384-391.

80. Seekamp A, van Griensven M, Hildebrandt F, Brauer N, Jochum M Martin M: The effect of trauma on neutrophil L-selectin expression and sL-selectin serum levels. Shock 2001, 15:254-260.

81. Goodman JC, Robertson CS, Grossman RG, Narayan RK: Elevation of tumor necrosis factor in head injury. J Neuroimmunol 1990, 30:213-217.

82. Maier B, Schwerdtfeger K, Mautes A, Holanda M, Muller M, Steudel WI, Marzi I: Differential release of interleukines 6,8 , and 10 in cerebrospinal fluid and plasma after traumatic brain injury. Shock 2001, 15:421-426.

83. Kirchhoff C, Buhmann S, Bogner V, Stegmaier J, Leidel BA, Braunstein V, Mutschler W, Biberthaler P: Cerebrospinal IL-10 concentration is elevated in non-survivors as compared to survivors after severe traumatic brain injury. Eur J Med Res 2008, 13:464-468.

84. Maskin B, Gammella D, Solari L, Videta W, Barboza MF, Geliz L, Rondina C: Early release of the antiinflammatory cytokine IL-10 in traumatic brain injury. Medicina (B Aires) 2001, 61:573-576.

85. Dietrich JB: The adhesion molecule ICAM-1 and its regulation in relation with the blood-brain barrier. J Neuroimmunol 2002, 128:58-68.

86. Laird MD, Vender JR, Dhandapani KM: Opposing roles for reactive astrocytes following traumatic brain injury. Neurosignals 2008, 16:154-164.

87. Cuschieri J, Gourlay D, Garcia I, Jelacic S, Maier RV: Hypertonic preconditioning inhibits macrophage responsiveness to endotoxin. $J$ Immunol 2002, 168:1389-1396.

88. Powers KA, Woo J, Khadaroo RG, Papia G, Kapus A, Rotstein OD: Hypertonic resuscitation of hemorrhagic shock upregulates the anti-inflammatory response by alveolar macrophages. Surgery 2003, 134:312-318.

89. Gushchin V, Stegalkina S, Alam HB, Kirkpatrick JR, Rhee PM, Koustova E: Cytokine expression profiling in human leukocytes after exposure to hypertonic and isotonic fluids. J Trauma 2002, 52:867-871.

90. Hatanaka E, Shimomi FM, Curi R, Campa A: Sodium chloride inhibits cytokine production by lipopolysaccharide-stimulated human neutrophils and mononuclear cells. Shock 2007, 27:32-35.

91. Hirsh MI, Hashiguchi N, Junger WG: Hypertonic saline increases gammadeltaT cell-mediated killing of activated neutrophils. Crit Care Med 2008, 36:3220-3225.

92. Ke QH, Zheng SS, Liang TB, Xie HY, Xia WL: Pretreatment of hypertonic saline can increase endogenous interleukin 10 release to attenuate hepatic ischemia reperfusion injury. Dig Dis Sci 2006, 51:2257-2263.

93. Oreopoulos GD, Bradwell S, Lu Z, Fan J, Khadaroo R, Marshall JC, Li YH, Rotstein OD: Synergistic induction of IL-10 by hypertonic saline solution and lipopolysaccharides in murine peritoneal macrophages. Surgery 2001, 130:157-165.

94. Powers KA, Zurawska J, Szaszi K, Khadaroo RG, Kapus A, Rotstein OD: Hypertonic resuscitation of hemorrhagic shock prevents alveolar macrophage activation by preventing systemic oxidative stress due to gut ischemia/reperfusion. Surgery 2005, 137:66-74.

95. Csuka E, Morganti-Kossmann MC, Lenzlinger PM, Joller $\mathrm{H}$, Trentz O, Kossmann T: IL-10 levels in cerebrospinal fluid and serum of patients with severe traumatic brain injury: relationship to IL-6, TNF-alpha, TGFbeta1 and blood-brain barrier function. J Neuroimmunol 1999, 101:211221.

96. Woiciechowsky C, Asadullah K, Nestler D, Eberhardt B, Platzer C, Schoning B, Glockner F, Lanksch WR, Volk HD, Docke WD: Sympathetic activation triggers systemic interleukin-10 release in immunodepression induced by brain injury. Nat Med 1998, 4:808-813.

97. Hess JR, Brohi K, Dutton RP, Hauser CJ, Holcomb JB, Kluger Y, MackwayJones K, Parr MJ, Rizoli SB, Yukioka T, et al: The coagulopathy of trauma: a review of mechanisms. J Trauma 2008, 65:748-754.

98. Zehtabchi S, Soghoian S, Liu Y, Carmody K, Shah L, Whittaker B, Sinert R: The association of coagulopathy and traumatic brain injury in patients with isolated head injury. Resuscitation 2008, 76:52-56.

99. Brummel-Ziedins K, Whelihan MF, Ziedins EG, Mann KG: The resuscitative fluid you choose may potentiate bleeding. J Trauma 2006, 61:1350-1358

100. Dubick MA, Bruttig SP, Wade CE: Issues of concern regarding the use of hypertonic/hyperoncotic fluid resuscitation of hemorrhagic hypotension. Shock 2006, 25:321-328. 
101. Reed RL, Johnston TD, Chen Y, Fischer RP: Hypertonic saline alters plasma clotting times and platelet aggregation. J Trauma 1991, 31:8-14

102. Hess JR, Dubick MA, Summary JJ, Bangal NR, Wade CE: The effects of $7.5 \%$ $\mathrm{NaCl} / 6 \%$ dextran 70 on coagulation and platelet aggregation in humans. J Trauma 1992, 32:40-44.

103. Tan TS, Tan KH, Ng HP, Loh MW: The effects of hypertonic saline solution (7.5\%) on coagulation and fibrinolysis: an in vitro assessment using thromboelastography. Anaesthesia 2002, 57:644-648.

104. Wilder DM, Reid TJ, Bakaltcheva IB: Hypertonic resuscitation and blood coagulation: in vitro comparison of several hypertonic solutions for their action on platelets and plasma coagulation. Thromb Res 2002, 107:255261.

105. Huang GS, Shih CM, Wu CC, Hu MH, Tsai CS, Liaw WJ, Chan SM, Li CY: Hypertonic Saline, Mannitol and Hydroxyethyl Starch Preconditioning of Platelets Obtained From Septic Patients Attenuates CD40 Ligand Expression In Vitro. J Trauma 2009.

106. Wu XH, Shi XY, Gan JX, Lu XG, Jiang GY, Zhou JF: Dynamically monitoring tissue factor and tissue factor pathway inhibitor following secondary brain injury. Chin J Traumatol 2003, 6:114-117.

107. Hagiwara S, Iwasaka H, Matsumoto S, Hasegawa A, Yasuda N, Noguchi T: In vivo and in vitro effects of the anticoagulant, thrombomodulin, on the inflammatory response in rodent models. Shock 2009.

doi:10.1186/1742-2094-7-5

Cite this article as: Rhind et al:: Prehospital resuscitation with hypertonic saline-dextran modulates inflammatory, coagulation and endothelial activation marker profiles in severe traumatic brain injured patients. Journal of Neuroinflammation 2010 7:5.

Publish with Bio Med Central and every scientist can read your work free of charge

"BioMed Central will be the most significant development for disseminating the results of biomedical research in our lifetime. "

Sir Paul Nurse, Cancer Research UK

Your research papers will be:

- available free of charge to the entire biomedical community

- peer reviewed and published immediately upon acceptance

- cited in PubMed and archived on PubMed Central

- yours - you keep the copyright 